\title{
Vegetation reflectance spectroscopy for biomonitoring of heavy metal pollution in urban soils
}

Kang Yua, ${ }^{a}$, Maarten Van Geel ${ }^{b}$, Tobias Ceulemans, Willem Geerts ${ }^{b}$, Miguel Marcos Ramosc, Cindy Serafimc, Nadine Sousac, Paula M.L. Castroc, Pierre Kastendeuch ${ }^{d}$, Georges Najjard, Thierry Ameglioe, Jérôme Ngaoe, Marc Saudreaue, Olivier Honnayb and Ben Somers ${ }^{a}$

aDepartment of Earth \& Environmental Sciences, KU Leuven, 3001, Heverlee, Belgium; E-mails: kang.yu@kuleuven.be; ben.somers@kuleuven.be

bDepartment of Biology, KU Leuven, 3001, Heverlee, Belgium. E-mails: maarten.vangeel@kuleuven.be; tobias.ceulemans@kuleuven.be; willem.geerts@student.kuleuven.be; olivier.honnay@kuleuven.be cUniversidade Católica Portuguesa, CBQF - Centro de Biotecnologia e Química Fina - Laboratório Associado, Escola Superior de Biotecnologia, Rua Arquiteto Lobão Vital, 172, 4200-374 Porto, Portugal. E-mails:

mmramos@porto.ucp.pt; nsousa@porto.ucp.pt; plcastro@porto.ucp.pt

dLaboratoire des sciences de l'ingénieur, de l'informatique et de l'imagerie, Strasbourg University, Illkirch, France. E-mails: kasten@unistra.fr; georges.najjar@unistra.fr

eUniversité Clermont Auvergne, INRA, PIAF, F-63000 Clermont Ferrand, France. E-mails: thierry.ameglio@inra.fr; jerome.ngao@inra.fr;

marc.saudreau@inra.fr

*Correspondence:

Kang Yu

E-mail: kang.yu@kuleuven.be

Division of Forest, Nature and Landscape

Department of Earth and Environmental Sciences

KU Leuven

Celestijnenlaan 200e - box 2411

3001 Leuven, Belgium 


\section{Abstract}

2 Heavy metals in urban soils may impose a threat to public health and may

3 negatively affect urban tree viability. Vegetation spectroscopy techniques

4 applied to bio-indicators bring new opportunities to characterize heavy metal

5 contamination, without being constrained by laborious soil sampling and lab-

6 based sample processing. Here we used Tilia tomentosa trees, sampled

7 across three European cities, as bio-indicators i) to investigate the impacts of

8 elevated concentrations of cadmium ( $\mathrm{Cd}$ ) and lead $(\mathrm{Pb})$ on leaf mass per area

9 (LMA), total chlorophyll content (Chl), chlorophyll $a$ to $b$ ratio (Chla:Chlb) and

10 the maximal PSII photochemical efficiency (Fv/Fm); and ii) to evaluate the

11 feasibility of detecting $\mathrm{Cd}$ and $\mathrm{Pb}$ contamination using leaf reflectance

12 spectra. For the latter, we used a partial-least-squares discriminant analysis

13 (PLS-DA) to train spectral-based models for the classification of $\mathrm{Cd}$ and/or $\mathrm{Pb}$

14 contamination. We show that elevated soil $\mathrm{Pb}$ concentrations induced a

15 significant decrease in the LMA and Chla:Chlb, with no decrease in Chl. We

16 did not observe pronounced reductions of $\mathrm{Fv} / \mathrm{Fm}$ due to $\mathrm{Cd}$ and $\mathrm{Pb}$

17 contamination. Elevated $\mathrm{Cd}$ and $\mathrm{Pb}$ concentrations induced contrasting

18 spectral changes in the red-edge $(690 \sim 740 \mathrm{~nm})$ region, which might be

19 associated with the proportional changes in leaf pigments. PLS-DA models

20 allowed for the classifications of $\mathrm{Cd}$ and $\mathrm{Pb}$ contamination, with a

21 classification accuracy of $86 \%($ Kappa $=0.48)$ and $83 \%($ Kappa $=0.66)$,

22 respectively. PLS-DA models also allowed for the detection of a collective

23 elevation of soil $\mathrm{Cd}$ and $\mathrm{Pb}$, with an accuracy of $66 \%$ (Kappa=0.49). This 
24 study demonstrates the potential of using reflectance spectroscopy for

25 biomonitoring of heavy metal contamination in urban soils.

26 Keywords: soil heavy metal contamination; leaf functional trait; vegetation

27 reflectance spectroscopy; red-edge position; bio-indicator

\section{Capsule}

29 Applying leaf reflectance spectroscopy to urban trees allows for biomonitoring

30 of heavy metal pollution and the classification of pollutants in urban soils. 


\section{Introduction}

32 Soil contamination is a widely spread problem across Europe

33 (European Commission, 2006). Among the most frequent soil pollutants are

34 heavy metals such as arsenic (As), cadmium (Cd), chromium (Cr), copper

$35(\mathrm{Cu})$, mercury $(\mathrm{Hg})$, lead $(\mathrm{Pb})$, zinc $(\mathrm{Zn})$, antimony $(\mathrm{Sb})$, cobalt $(\mathrm{Co})$ and

36 nickel $(\mathrm{Ni})$, which accumulate on the soil surface and transfer to deeper soil

37 layers where they can infiltrate into the groundwater (Vince et al., 2014).

38 Plants growing on heavy metal polluted soils passively take up heavy metals,

39 jeopardizing their growth and negatively affecting other organisms feeding

40 on the plants (Panagos et al., 2013; Tóth et al., 2016). Furthermore,

41 elevated concentrations of these heavy metals in agricultural or urban soils

42 endanger food safety and public health (Poggio et al., 2009; Tóth et al., 43 2016).

$44 \quad$ Urban soils typically contain elevated concentrations of $\mathrm{Cd}, \mathrm{Cu}, \mathrm{Zn}$

45 and $\mathrm{Pb}$, originating from anthropogenic activities such as traffic and industrial

46 emissions (Gallagher et al., 2008; Li et al., 2001; Poggio et al., 2009;

47 Pourkhabbaz et al., 2010; Vince et al., 2014). Cd and Pb are the most

48 common heavy metals resulting from road traffic, which is attributed to the

49 historical use of $\mathrm{Pb}$ as a gasoline additive (Kovarik, 2005) and Cd

50 accumulation which is mainly due to abrasion of tires (Andersson et al.,

51 2010; Vince et al., 2014). Cd and Pb are toxic for plants, animals and

52 humans (Pandit et al., 2010; Poggio et al., 2009). Cd accumulates in human

53 body and can cause nephropathy, pulmonary lesions and lung cancer after

54 long period of exposure (Poggio et al., 2009). Pb increases blood pressure 
55 and damages liver, kidney and fertility, and most severely it reduces brain

56 functioning and induces hyperactivity and hearing loss in children (Poggio et

57 al., 2009). Therefore, it is vital to detect elevated concentrations of Cd and

$58 \mathrm{~Pb}$ in urban soils.

59 Measuring heavy metals is typically based on the collection of soil or

60 road dust samples, which is labor intensive and costly, especially when

61 monitoring heavy metal contamination at larger spatial scales (Wei and Yang,

62 2010). In European countries, the estimated total annual cost related to

63 monitoring and remediating soil contaminants is 17.3 billion euros (European

64 Commission, 2006), and around $81 \%$ of the expenditures is spent on

65 remediation measures (Liedekerke et al., 2014). Consequently, only up to

$6615 \%$ is available to be spent on site investigations (Liedekerke et al., 2014),

67 implying that there is a need for more cost-effective investigation methods to

68 evaluate spatial and temporal heterogeneity of soil pollution. Soil near-

69 infrared (NIR) spectroscopy has been applied for the detection of heavy

70 metals at relatively low cost. However, this method requires intensive soil

71 sampling (Pandit et al., 2010; Shi et al., 2014). Therefore, a spatially explicit

72 characterization of heavy metal contamination at large scales is constrained

73 by the capacity of sampling and sample processing, especially in urban areas

74 characterized by sealed soil surfaces and highly heterogeneous land-use

75 types.

76 Bio-indicators are living organisms that can be used to assess the

77 quality of the environment (Holt and Miller, 2010; Parmar et al., 2016).

78 Urban vegetation can be used as bio-indicators for monitoring air and soil 
79 pollution (Ho, 1990; Khavanin Zadeh et al., 2013; Sawidis et al., 2011).

80 Plants concentrate metal elements in their above ground parts, which are

81 indicative of elevated soil heavy metal concentrations. Furthermore, heavy

82 metals can inhibit plant growth (Giulia et al., 2013; Horler et al., 1980), and

83 decrease chlorophyll content and biomass productivity (Gallagher et al.,

84 2008; Manios et al., 2003). Cd and Pb often limit plant growth by altering

85 leaf internal structures (Giulia et al., 2013; Pourkhabbaz et al., 2010). For

86 instance, Cd can reduce cell wall extensibility and relative water content

87 (Barceló and Poschenrieder, 1990). Pb can reduce not only the leaf

88 expansion but also the total chlorophyll content and efficiency of PSII electron

89 transport (Kastori et al., 1998). Overall, heavy metal toxicity causes multiple

90 direct and indirect effects on various physiological functions and on the

91 morphology of plants (Barceló and Poschenrieder, 1990), reflected in

92 changes of leaf functional traits.

93 Metal induced morphological and physiological changes can further

94 alter vegetation absorbance and reflectance characteristics (Horler et al.,

95 1980). Typically, heavy metal contamination induces most notable changes

96 in the visible and NIR spectral regions, and thus reflectance spectroscopy

97 holds great promise for evaluating the impact of heavy metal contamination

98 on vegetation (Clevers et al., 2004; Kooistra et al., 2004, 2003; Rosso et al.,

99 2005). By applying reflectance spectroscopy to monitoring candidate bio-

100 indicators located at multiple sites in urban areas, researchers have been

101 able to detect polluted sites (Khavanin Zadeh et al., 2013). Previous studies

102 have investigated the effect of individual metals on vegetation spectral 
103 responses, e.g., canopy reflectance in response to manipulated pot-soil Cd 104 changes (Rosso et al., 2005). However, different metals may induce similar 105 or contrasting spectral responses (Amer et al., 2017; Horler et al., 1980;

106 Manios et al., 2003). Some studies have focused on spectral response in 107 specific spectral bands such as the red-edge region $(690 \sim 740 \mathrm{~nm})$, which 108 has been used to estimate plant chlorophyll variations under stress due to 109 heavy metals (Clevers et al., 2004; Rosso et al., 2005). The red-edge 110 position (REP) is defined as the position generating the maximum slope 111 (inflection point) of the reflectance spectra (or maximum first derivative 112 reflectance) in the red-edge region (Clevers et al., 2004; Horler et al., 1983), 113 and has been found to be negatively related to soil Pb concentration (Clevers 114 et al., 2004; Kooistra et al., 2004). Overall, associating soil heavy metal 115 pollution with a range of plant functional and reflectance characteristics 116 provides a cost-effective method for assessing heavy metal pollutions.

117 However, there is still a lack of vegetation reflectance spectroscopy studies

118 that bio-monitor $\mathrm{Cd}$ and $\mathrm{Pb}$ contamination across a variety of urban 119 environments, especially for monitoring contamination due to multiple 120 metals.

$121 \quad$ Here we tested Tilia tomentosa as a bio-indicator for elevated soil Cd 122 and $\mathrm{Pb}$ concentrations. Selecting 187 study trees cross three European cities 123 (Leuven, Porto and Strasbourg), our objectives were: i) to assess the 124 impacts of elevated concentrations of $\mathrm{Cd}$ and $\mathrm{Pb}$ on leaf mass per area 125 (LMA), total chlorophyll content (Chl), chlorophyll $a$ to $b$ ratio (Chla:Chlb) and 126 the maximal PSII photochemical efficiency (Fv/Fm); and ii) to investigate the 
127 feasibility of using leaf reflectance spectroscopy and partial-least-squares

128 discriminant analysis for biomonitoring soil $\mathrm{Cd}$ and $\mathrm{Pb}$ contamination.

\section{Materials and Methods}

130 Sampling of leaf and soil and heavy metal measurements

131 We conducted soil and leaf sampling in summer 2017 and randomly selected

13219 sites and $187 \mathrm{~T}$. tomentosa trees across three medium sized cities

133 (Leuven (Belgium): $\mathrm{n}=64$; Porto (Portugal), $\mathrm{n}=67$; Strasbourg (France): $\mathrm{n}$

$134=56$ ). We randomly selected trees for sampling, and the trunk diameter

135 ranged $5-130 \mathrm{~cm}$. For each tree, we sampled the top soils $(0-10 \mathrm{~cm})$ at three

136 random locations surrounding the trunk, and the three locations are mixed

137 for metal measurements. We sampled 15 leaves at three random positions in

138 each tree and stored the leaf samples in a cool box with ice. We performed

139 soil sampling once, while leaf sampling was performed multiple times

140 throughout the growing season for a subset of trees in Leuven and

141 Strasbourg.

142 Heavy metal concentrations in the soil were measured by digesting 50

$143 \mathrm{mg}$ of dried and sieved soil with $7.5 \mathrm{ml}$ concentrated hydrochloric acid and

$1442.5 \mathrm{ml}$ concentrated nitric acid. The digested solution was diluted to $10 \mathrm{ml}$

145 and measured with ICP-OES. For quality control of soil metal analysis, an

146 internal soil standard was run parallel with the soil samples, which deviated

147 less than $5 \%$ of the known composition. In this study, we focused on Cd and

$148 \mathrm{~Pb}$, as these were the heavy metals that reached the toxicity thresholds

149 (Table 1). 
150 Identification of contamination based on soil heavy metal thresholds

151 Soil heavy metal contamination levels were identified based on published

152 threshold standards (Tóth et al., 2016) released by the Ministry of the

153 Environment, Finland (MEF, 2007). We grouped the samples into two classes

154 - non-contaminated and contaminated, subjected to individual metals (Table

155 1). Soil samples and corresponding leaf spectral observations (section 2.3)

156 were grouped into four classes according to $\mathrm{Pb}$ contamination following the

157 MEF standard (MEF, 2007). The four classes included class 0 being non-

158 contaminated $(\mathrm{Pb}<60 \mathrm{mg} / \mathrm{kg})$, class 1 of low contamination $(60 \leqslant \mathrm{~Pb}<200$

$159 \mathrm{mg} / \mathrm{kg}$ ), class 2 of medium contamination $(200 \leqslant \mathrm{~Pb}<750 \mathrm{mg} / \mathrm{kg}$ ) and class

1603 of high contamination ( $\mathrm{Pb} \geqslant 750 \mathrm{mg} / \mathrm{kg}$ ).

161 We also defined four contamination classes subjected to both $\mathrm{Cd}$ and

$162 \mathrm{~Pb}$ contamination by re-grouping of the $\mathrm{Cd}$ and $\mathrm{Pb}$ binary classes (Table $\mathrm{S} 1$ ),

163 i.e., four $\mathrm{CdxPb}$ classes including the non-contaminated (class 0), Cd

164 contaminated only (class 1 ), Pb contaminated only (class 2 ) as well as when

165 both $\mathrm{Cd}$ and $\mathrm{Pb}$ are over the thresholds (class 3 ).

166 Leaf reflectance and functional traits

167 Leaf reflectance was measured using an ASD FieldSpec 3 spectroradiometer

168 (ASD Inc., Longmont, CO, USA) connected to a Plant Probe and Leaf Clip

169 Assembly (ASD Inc., Longmont, CO, USA). It allows for reflectance

170 measurement in a spectral range of $350-2500 \mathrm{~nm}$ with a band width of 1

$171 \mathrm{~nm}$. Next, we measured the leaf maximal PSII photochemical efficiency

172 (Fv/Fm, ratio of the variable fluorescence to the maximal fluorescence) using 
173 a chlorophyll fluorescence meter (Handy PEA, Hansatech Instruments Ltd.,

174 Pentney, UK), combined with a leaf clip that allows for dark adaption (25

$175 \mathrm{~min}$ ). Then, we measured the leaf area using a flatbed scanner, followed by

176 oven dry for 3 days, allowing to determine leaf mass per area (LMA). In

177 total, aggregated per tree and sampling time, collected leave samples

178 allowed for further statistical analysis on a sample size of 333 for reflectance

179 and functional traits. The 333 observations of reflectance spectra and

180 functional traits were grouped into their contamination classes subjected to

181 the soil heavy metal contamination classes as defined in the Section 2.2.

182 A random subset of the leaf samples $(n=53)$ were used to determine

183 the total chlorophyll ( $\mathrm{Chl}$ ) and carotenoid (Car) content. Leaf round discs with

184 a diameter of $28.6 \mathrm{~mm}$ were punched from the leaf samples using a paper

185 punch. Chla, Chlb and Car were extracted with a mortar and pestle in $80 \%$

186 acetone and their concentrations determined by measuring the solution

187 absorbance (A) at wavelengths $470,646.8$ and $663.2 \mathrm{~nm}$ using a UV-VIS

188 spectrophotometer (Shimadzu 1650 PC, Kyoto, Japan) according to Eqs. (1-

189 3) (Lichtenthaler, 1987).

190

$$
\text { Chla }=12.25 * A_{663.2}-2.79 * A_{646.8} \#(1)
$$

191

$$
\text { Chlb }=21.50 * A_{646.8}-5.10 * A_{663.2} \#(2)
$$

$$
\operatorname{Car}=\frac{1000 * A_{470}-1.82 * \text { Chla }-85.02 * \text { Chlb }}{198} \#(3)
$$


For quality control of chlorophyll analysis, we performed parallel

194 measurements in 12 samples, and the average standard error was lower

195 than 5\%.

196 Spectral and statistical analysis

197 To highlight the metal-induced spectral variations, we calculated the

198 reflectance relative differences between group means for the contaminated

199 and non-contaminated classes subjected to $\mathrm{Cd}$ and $\mathrm{Pb}$ contamination. We

200 also applied first derivatives to the reflectance, focusing mainly on the red-

201 edge region, to derive the red-edge inflection point (REIP) and evaluate the

202 metal induced red-edge shifts (Clevers et al., 2004).

203 Partial least squares (PLS) regression is a multivariate method for

204 relating two data matrices, $X$ and $Y$, i.e., explanatory and response matrices,

205 by extracting latent variables (components) to model the variations of both

206 matrices (Wold et al., 2001). The PLS regression can reduce high

207 dimensional data (e.g. hyperspectral) to a small number of latent variables

208 which serve as new predictors on which the response variable is regressed

209 (Rosipal and Krämer, 2006). Partial least squares discriminant analysis (PLS-

210 DA) is a variant used when the response variable is categorical. We used

211 PLS-DA for the classification of metal contamination classes. PLS-DA models

212 were applied to four types of data, (i) the original reflectance spectral, and

213 three pre-processed spectral data including (i) first derivative (ii), standard

214 normal variate SNV and (iii) continuum removal (CR) precede applying the

215 PLS-DA models. PLS-DA model calibration was first initiated on the entire

216 dataset for the full spectrum with 10 components. The initial model was 
217 trained using a 10-fold cross-validation with 99 times of permutations,

218 allowing for determination of the optimal number of components and the

219 spectral bands yielding a variable importance in projection (VIP) $\geqslant 0.8$.

220 For an independent validation, the entire dataset was randomly split

221 into the training and test subsets, with a sample size being $2 / 3(n=215)$ and

$2221 / 3(n=118)$ of the total observations $(n=333)$, respectively. The VIP $\geqslant 0.8$

223 spectral bands were then used to train and test models on the two subsets,

224 respectively.

225 PLS-DA Model classification accuracy was evaluated using the overall

226 accuracy (Eq. 4) and kappa coefficient (Eq. 5), as well as for assessing the

227 classification for individual classes using the producer's (Eq. 7) and user's

228 accuracies (Eq. 8),

229

230

$$
\text { Accuracy }=(T P+T N) /(T P+T N+F P+F N) \#(4)
$$

$$
p_{e}=\frac{(T N+F P) \times(T N+F N)+(F N+T P) \times(F P+T P)}{(T P+T N+F P+F N)^{2}} \#(6)
$$

$$
\text { Producer Accuracy }=T P /(T P+F P) \#(7)
$$

$$
\text { User Accuracy }=T P /(T P+F N) \#(8)
$$

234 where the letters $T$ and $F$ denote true and false, respectively, and $P$ and $N$

235 denote positive and negative, respectively, $p_{a}$ is the actual agreement

236 (identical to accuracy), whereas $p_{e}$ is the expected agreement by chance

237 (random accuracy) that can be calculated as Eq. (6). 
We used linear mixed models to test whether elevated soil heavy

239 metals affect the leaf functional traits. We defined the metal contamination

240 classes, i.e., binary or multi-class, as the fixed effect factor and defined city

241 and sampling site as random effect factors in the mixed models. All analyses

242 were performed in the R programming environment (R Core Team, 2016).

243 The R package 'Ime4' (Bates et al., 2015) was used for running the mixed

244 models, and the package 'Ismeans' (Lenth, 2016) was used for post-hoc

245 analysis of pairwise comparisons between the contaminated classes based on

246 Tukey's test. PLS-DA was implemented using the package 'mixOmics' (Rohart 247 et al., 2017).

\section{Results and Discussion}

249 Heavy metal effects on leaf functional traits

250 Elevated $\mathrm{Pb}$ and $\mathrm{Cd}$ concentrations had a significant effect on LMA of $T$.

251 tomentosa trees (Table 2). Soil Cd contamination did not induce significant

252 changes in LMA (Fig. 1a), whereas Pb contamination significantly decreased

253 LMA (Fig. 1b). Generally, Cd and Pb stress leads to damages to chloroplasts

254 and thylakoid membranes in plants (Shen et al., 2016; Wu et al., 2014),

255 which often causes reduced leaf growth such as small leaf size and small

256 stomata (Shi and Cai, 2009), as well as thin cuticles of leaf surfaces

257 (Pourkhabbaz et al., 2010). Therefore, elevated Pb concentrations could have

258 reduced leaf thickness and thus decreased LMA. Cd also induces changes in

259 leaf structural properties, while Cd concentrations measured in this study

260 might still be below the threshold that induces significant inhibition of leaf

261 expansion. 
262 Elevated soil $\mathrm{Pb}$ induced significant changes in leaf total $\mathrm{Chl}$ content, 263 Chla to Chlb ratio (Chla:Chlb) and Fv/Fm, whereas Cd and other metals did 264 not yield significant changes (Table 2). Decrease in leaf Chl content is often 265 associated with photoinhibition and reduction of the photosynthetic capacity 266 (Shen et al., 2016). Chla:Chlb decreased significantly along with the increase 267 in soil Pb concentration (Fig. 2), suggesting that Chla was more suppressed 268 compared to Chlb (Nie et al., 2016). Similarly, a significant reduction of 269 Chla:Chlb has been found in Torreya grandis (Shen et al., 2016) and Typha 270 latifolia plants (Manios et al., 2003) treated with a high concentration of Cd 271 and $\mathrm{Pb}$, suggesting increases in chlorophyll hydrolysis due to the toxic effect

272 (Manios et al., 2003). Results may differ for different plant species, for 273 instance in a greenhouse environment, Horler et al. (1980) observed a 274 significant decrease of Chla:Chlb in pea leaves due to elevated Cd 275 concentrations, but no changes following elevated Pb (Horler et al., 1980).

$276 \mathrm{Cd}$ and $\mathrm{Pb}$ contamination induced a decrease in Fv/Fm (Fig. 3a, b), 277 whereas Fv/Fm appeared to be not sensitive to low-level Pb contamination 278 (Fig. 3d), suggesting that $\mathrm{Cd}$ and Pb stress may induce photosynthesis 279 inhibition. Similarly, Cd was found to affect Fv/Fm in the wetland plant 280 species Salicornia virginica (Rosso et al., 2005) and in the turf grass species 281 Festuca arundinacea Schreb (Huang et al., 2017). Generally, the observed 282 decrease in $\mathrm{Fv} / \mathrm{Fm}$ in plants subjected to $\mathrm{Cd} / \mathrm{Pb}$ stress is associated with the 283 photoinhibition of PSII, as a result of the overproduction of reactive oxygen 284 species (ROS) (Huang et al., 2017; Shen et al., 2016). However, a significant 285 decrease in Fv/Fm may not always be observable if $\mathrm{Cd} / \mathrm{Pb}$ concentration does 
286 not exceed a high threshold (Huang et al., 2017; Shen et al., 2016). Giulia et 287 al. (2013) found that a high soil Pb concentration did not decrease Fv/Fm in 288 Q. ilex plants, and they argued that these metals may not significantly alter 289 functionality of the photosynthetic apparatus. Similarly, Shi and Cai (2009) 290 reported that Fv/Fm was not affected in peanut plants treated with a high 291 concentration of Cd. Therefore, the effect of heavy metals on Fv/Fm might 292 depend largely on metal type, concentration and plant species.

$293 \quad$ Mixed models for multi-class $\mathrm{CdxPb}$ and $\mathrm{Pb}$ contamination showed 294 much more pronounced effects on LMA and Chla:Chlb than on Fv/Fm and leaf 295 total Chl content (Table 3), which suggests that heavy metals induced more 296 structural changes and proportional changes in leaf biochemicals than the 297 quantity changes of individual components. An increase in leaf total Chl 298 content and Fv/Fm was observed at a relative low-level $\mathrm{Pb}$ or $\mathrm{Cd} \times \mathrm{Pb}$ 299 contamination (Table 3), suggesting that heavy metals impose complicated 300 effects on photosynthesis and that $\mathrm{Cd}$ and $\mathrm{Pb}$ may increase the PSII quantum 301 yield within a certain range of low concentrations (Ouyang et al., 2012; Shen 302 et al., 2016).

303 The effect of soil heavy metals on leaves or the content of heavy metal 304 accumulation in the leaves might be related to the age of trees (Doganlar et 305 al., 2012). To test whether tree age difference affect the observed effects of $306 \mathrm{Cd}$ and $\mathrm{Pb}$ on leaf functional traits in this study, we used trunk diameter as a 307 proxy of tree age and added it as an additional random factor in the mixed 308 models (Table S2 and Table S3). Results suggest that the observed effects of 
$309 \mathrm{Cd}$ and $\mathrm{Pb}$ on $\mathrm{T}$. tomentosa leaves was not significantly influenced by tree 310 age.

311 Reflectance and first derivatives in response to heavy metals

312 Elevated soil Cd concentrations yielded relatively large variations in leaf

313 reflectance centered at the 500, 680 and $720 \mathrm{~nm}$ bands (Fig. 4a), whereas

314 elevated $\mathrm{Pb}$ yielded large variations at the 550 and $700 \mathrm{~nm}$ bands (Fig. 4b).

315 In the red-edge region, $\mathrm{Cd}$ had a large effect on reflectance at the red-edge

316 center ( $720 \mathrm{~nm})$, whereas $\mathrm{Pb}$ had a large effect on reflectance ranging from

317 the red absorption to the beginning of the red-edge bands $(680 \sim 700 \mathrm{~nm})$.

318 Over the full spectrum, soil $\mathrm{Pb}$ contamination induced larger variations

319 ( $\pm 10 \%$, Fig. 4b) compared to Cd contamination ( $\pm 5 \%$ ) (Fig. 4a), which

320 might be attributed to the fact that $\mathrm{Pb}$ contamination was severer than $\mathrm{Cd}$ in

321 this study. Cd concentration was slightly higher than the threshold (1

$322 \mathrm{mg} / \mathrm{kg}$ ), but was much lower than the 'low guideline' of contamination level

$323(10 \mathrm{mg} / \mathrm{kg})$ at which ecological or health risks present (Tóth et al., 2016).

324 The decrease in the NIR region (750 1400 nm) was associated with

325 elevated $\mathrm{Cd}$ and $\mathrm{Pb}$ concentrations. This might be attributed partly to the

326 decreased LMA because contaminated trees often have a much thinner outer

327 epidermal layer and thus thinner leaves (Pourkhabbaz et al., 2010), although

328 the effect of Cd on LMA observed in this study was marginal (Fig. 1). Metal-

329 induced decreases in leaf NIR reflectance might be associated mainly with

330 the changes in leaf internal structural properties which decrease the internal 
331 light scattering and increase the transmittance of leaves (Horler et al., 1980;

332 Kumar et al., 2001).

333 The first derivative reflectance in the visible-to-NIR bands showed two

334 major peaks centered at 530 and $720 \mathrm{~nm}$ (Fig. S1). In the red-edge spectral

335 region, Cd contamination induced a shift of absorbance features towards the

336 shorter wavelengths (Fig. S1a). In contrast, Pb contamination induced a red-

337 edge shift to the longer wavelengths (Fig. S1b). In addition to the red-edge

338 bands, $\mathrm{Pb}$ contamination also yielded large variations in the first derivative

339 reflectance at the green bands, suggesting a more pronounced change of the

340 overall shape of reflectance (cf. Fig. 4). As shown in the first derivative

341 reflectance, $\mathrm{Pb}$ contamination also induced a shift in the green edges (both

342 sides of the green peak) compared to Cd contamination. This might explain

343 the observed decrease in the Chla:Chlb ratio (Fig. 2), since absorption at the

344 green edge bands is related to Chlb variations (Kumar et al., 2001).

345 The extracted REIP showed contrasting changes in the $\mathrm{Cd}$ and $\mathrm{Pb}$

346 contaminated trees, with decreasing and increasing trends, respectively (Fig.

347 S2), which confirms the contrasting effects of $\mathrm{Cd}$ and $\mathrm{Pb}$ contamination on

348 the red-edge reflectance. Heavy-metal induced REIP changes, or red-edge

349 shifts, have been found to depend to some degree on plant species and

350 sampling sites (Kooistra et al., 2004). Normally, a decreased REIP can be

351 observed when plant stress induces a reduction in leaf total $\mathrm{Chl}$ content

352 (Horler et al., 1983). However, here we did not observe obvious Chl

353 reduction associated with $\mathrm{Cd}$ or $\mathrm{Pb}$ contamination. Therefore, the REIP

354 variations observed here were more likely associated with the proportional 
355 changes in the Chla:Chlb ratio, in combination with changes in leaf 356 structures.

357 PLS-DA model calibration for binary and multi-class classifications

358 In the binary classifications, the PLS-DA calibration models for Cd-

359 contamination classification yielded a total accuracy of $84.1 \sim 86.5 \%$ (kappa $=$

$360 \quad 0.46 \sim 0.49$, Table S4). PLS-DA models for $\mathrm{Pb}$ contamination yielded a total

361 accuracy of $72.7 \sim 77.8 \%$ (kappa $=0.46 \sim 0.57$ ). For the multi-class

362 classification of $\mathrm{CdxPb}$-mixed contamination, PLS-DA models yielded a total 363 accuracy of $43.2 \sim 66.1 \%$ (kappa $=0.24 \sim 0.49$, Table S4). PLS-DA models for 364 the multi-class classification of $\mathrm{Pb}$ yielded a total accuracy of $52.0 \sim 64.0 \%$ 365 (kappa $=0.29 \sim 0.43)$. The best classifications for individual metals are 366 illustrated in confusion-matrix plots (Fig. 5).

367 The best model for Cd correctly classified the Cd class 0 with a 368 producer and use accuracy of $86 \%$ and $97 \%$, respectively, and were $77 \%$ 369 and $43 \%$ for the Cd class 1 (Fig. 5a). The producer and use accuracy for the $370 \mathrm{~Pb}$ class 0 were $88 \%$ and $67 \%$, respectively, and $77 \%$ and $90 \%$ for the $\mathrm{Pb}$ 371 class 1 (Fig. 5 b). The best model for $\mathrm{Cd} \times \mathrm{Pb}$ yielded a relatively low user 372 accuracy in predicting the classes 1 and 3 (Fig. 5c), which however, accounts 373 for a very small proportion of the total observations. The best model for 374 multi-class $\mathrm{Pb}$ contamination yielded a relatively high producer accuracy for 375 the classes 0 and 3 (Fig. 5d), with $80 \%$ and $100 \%$, respectively. In contrast, 376 the model yielded a higher user accuracy for the classes 0 and 1 than for the 377 classes 2 and 3. The low user accuracy for the Pb classes 2 and 3 was mainly 
378 due to the small sample size of high $\mathrm{Pb}$ concentrations, which consists of only

37917 and 4 observations for the classes 2 and 3, respectively.

380 Overall, the high producer accuracy, paired with relatively low user

381 accuracy for a relatively high metal concentration was rather encouraging,

382 since our models slightly tended to overestimate the observed contamination

383 rather than underestimate the elevated contamination. This implies a high

384 probability of detecting the elevated concentrations of soil heavy metals.

385 PLS-DA model validation using full spectrum and VIP-bands

386 Compared to model calibration accuracies, model validation based on the full

387 spectrum produced comparable accuracies (Table S5). In binary

388 classifications, models for $\mathrm{Pb}$ contamination yielded higher kappa coefficients

389 than the models for Cd contamination. In multi-class classifications, model

390 validation showed improved total accuracies and kappa coefficients (Table

391 S5), suggesting the potential of using calibrated PLS-DA models for detecting

392 elevated soil $\mathrm{Cd}$ and $\mathrm{Pb}$ concentrations.

393 Validation of models trained with the VIP $(\geqslant 0.8)$ bands showed

394 slightly improved kappa values and total accuracies compared to the full use

395 of bands (Table S5). The importance of individual spectral bands in the

396 classification is indicated by the VIP scores for individual metals (Fig. 6). Cd

397 contamination yielded relatively high VIP scores at the red-edge (730 nm)

398 and SWIR bands (1300 nm, $1650 \mathrm{~nm}$ ) compared to Pb contamination,

399 suggesting unique spectral responses to elevated soil $\mathrm{Cd}$ in these bands (Fig.

400 6). Pb contamination yielded higher VIP scores at the green (530 nm) and 
401 the beginning of red-edge $(700 \mathrm{~nm})$, suggesting that $\mathrm{Pb}$ contamination

402 induced more pronounced responses in the visible bands. For the binary 403 classifications, VIP-based PLS-DA models yielded higher accuracies for Pb-

404 contamination classification $(k a p p a=0.66)$ than for $\mathrm{Cd}(\mathrm{kappa}=0.39$, Table

405 S5). For multi-class classifications, the VIP-based PLS-DA models yielded 406 comparable accuracies by using a much less amount of bands compared to 407 the use of full spectral bands.

$408 \quad$ Model validation results showed that selecting a set of influential bands

409 (VIP $\geqslant 0.8$ ) allowed for maintaining classification accuracy and improving

410 model-use and computational efficiencies. Within a limited number of

411 observations, by randomly dividing independent training and testing subsets

412 of observations, our results suggest that spectrally calibrated PLS-DA models

413 have great potential of applying to future scenarios for monitoring heavy

414 metals.

415 Comparison between reflectance pre-processing methods

416 The kappa coefficient is a balanced measure compared to the use of the

417 producer-, user- and total accuracies, especially when the observations in

418 difference classes are highly imbalanced such as in this study. Hence, we

419 evaluated the three spectra-preprocessing methods according to the kappa

420 values. Model calibration and validation both showed that the first derivatives

421 yielded the highest kappa values compared to the use of the original and

422 SNV reflectance data (Table S4 and Table S5). 
Using a different number of components might induce some degree of

424 variation in model accuracies, although we used the cross-validation (CV)

425 procedure. In addition to the CV-optimized number of components, model

426 calibration and validation were repeated by using a fixed number of

427 components (Table S6, Table S7 and Table S8). Results showed that the first

428 derivative reflectance yielded the highest kappa coefficients, followed by the

429 CR reflectance and the original reflectance (Fig. S3). The SNV reflectance did

430 not yield improvement compared to the original reflectance data, suggesting

431 that the SNV process may mask subtle spectral responses subjected to

432 individual metals. Overall, PLS-DA models based on the first derivative

433 reflectance produced the best classifications, which also suggests that heavy

434 metals have induced complicated effects on leaf biochemical and structural

435 properties that lead to light absorption changes/shifts over the full spectrum.

$436 \quad$ First derivative spectra of leaves have been proven to be effective in

437 eliminating background signals and for resolving overlapping spectral

438 features (Demetriades-Shah et al., 1990), which is useful to detect plant

439 stresses or estimate pigment changes (Rundquist et al., 1996; Smith et al.,

440 2004). Also, first derivative reflectance has better discrimination power

441 compared to the original reflectance by characterizing the rate of change of

442 reflectance with respect to wavelengths (Bao et al., 2013; Lassalle et al.,

443 2018; Smith et al., 2004). Typically, derivative analysis may facilitate the

444 detection of changes that might be masked in the original spectra by the

445 presence of plant intrinsic co-variations (Horler et al., 1983). For instance,

446 derivative spectra in the visible region may enable to detect subtle changes 
447 in leaf pigment balance associated with physiological disorders or vegetation

448 types (Bandaru et al., 2016; Demetriades-Shah et al., 1990; Pu, 2011).

449 Derivative analysis can be particularly useful for remotely biomonitoring

450 heavy metal using reflectance spectra measured from above the vegetation

451 canopy (Wang et al., 2018). Canopy spectra first derivatives eliminate the

452 additive noises (baseline shifts) induced by illumination instability, canopy

453 structural or soil background influences (Demetriades-Shah et al., 1990;

454 Gnyp et al., 2014; Kochubey and Kazantsev, 2012; Pu, 2011), thereby

455 improving the accuracy for quantification of canopy biochemical or

456 physiological changes (Jin and Wang, 2016; O'Connell et al., 2014).

457 Moreover, PLS modeling further facilitates the use of features of the full

458 derivative spectrum for the characterization of vegetation undergoing

459 changes or stresses.

460 Apparently, PLS-DA models for Pb-contamination classifications

461 exclusively produced higher kappa values than for Cd contamination

462 classifications, across different cases of spectra-preprocessing methods,

463 model calibration (Fig. S3a) and validation (Fig. S3b), as well as when using

464 a subset of VIP-bands (Fig. S3c). This can be attributed to the data

465 imbalance between the $\mathrm{Cd}$ - and $\mathrm{Pb}$-contamination levels, which, however,

466 shows a great promise of the proposed approach for spectroscopic detection

467 of elevated soil heavy metals, given that a diverse set of observations are 468 used for model calibration. 


\section{Conclusions}

470 This study used T. Tomentosa trees growing in three European cities as bio-

471 indicators of soil heavy metal contamination, and evaluated whether tree

472 spectra responses were able to reflect the elevated metal concentrations.

473 Results showed that elevated soil $\mathrm{Cd}$ and $\mathrm{Pb}$ concentrations led to decrease in

474 the leaf mass per area (LMA) and the chlorophyll $a$ to $b$ ratio (Chla:Chlb),

475 while no significant reduction in leaf total chlorophyll (Chl) and the maximal

476 PSII photochemical efficiency (Fv/Fm). Soil Pb contamination was severer

477 and showed more pronounced effect on LMA, Fv/Fm, Chl and Chla:Chlb than

478 did the Cd contamination in the studied sites.

$479 \quad \mathrm{Cd}$ and $\mathrm{Pb}$ contamination induced specific changes in leaf reflectance

480 and the reflectance first derivatives, particularly in the red-edge spectral

481 region. Partial least squares discriminant analysis (PLS-DA) models calibrated

482 using leaf reflectance showed promise for detecting soil $\mathrm{Cd}$ and $\mathrm{Pb}$

483 contamination in urban areas. PLS-DA models based on reflectance first

484 derivatives allowed for the best classification of $\mathrm{Cd}$ and $\mathrm{Pb}$ contamination.

485 This study shows that elevated soil heavy metals can be monitored by

486 measuring leaf spectra of trees. This holds great potential for mapping urban

487 heavy metal contamination by measuring urban vegetation using high-

488 resolution spectrometers onboard airborne or drone platforms. Future work

489 should investigate whether our findings can be extrapolated to broader scales

490 by using canopy level reflectance data and a diverse set of plant species as

491 bio-indicators. Multi-temporal investigations of the quantitative relationships

492 between the practical content of heavy metals in leaves and reflectance 
spectroscopic measures are also needed to understand metal translocation

494 from soil to vegetation and for dynamic biomonitoring of heavy metal

495 contamination.

\section{Acknowledgements}

497 This research was funded through the 2015-2016 BiodivERsA COFUND call

498 for research proposals, with the national funders BelSPo (BE), FWO (BE), FCT

499 (PT) and through the project UID/Multi/50016/2013. We thank Remi

500 Chevalier, the greenery service of the Cities of Leuven, Porto (Câmara

501 Municipal do Porto) and Strasbourg for their assistance in fieldwork and

502 measurements. The authors thank Remi Chevalier and Yasmin Vanbrabant

503 for their assistance in chlorophyll analysis.

504 Declarations of interest

505 None.

506 References

507 Amer, M., Tyler, A., Fouda, T., Hunter, P., Elmetwalli, A., Wilson, C., Mario

508

509

510

511

512

513

514

515

516

517

518

519

520

521 VALLEJO-MARIN, 2017. Spectral Characteristics for Estimation Heavy Metals Accumulation in Wheat Plants and Grain. Sci. Pap. Ser. Manag. Econ. Eng. Agric. Rural Dev. 17, 47-55.

Andersson, M., Ottesen, R.T., Langedal, M., 2010. Geochemistry of urban surface soils - Monitoring in Trondheim, Norway. Geoderma 156, 112-118. https://doi.org/10.1016/j.geoderma.2010.02.005

Bandaru, V., Daughtry, C.S., Codling, E.E., Hansen, D.J., White-Hansen, S., Green, C.E., 2016. Evaluating Leaf and Canopy Reflectance of Stressed Rice Plants to Monitor Arsenic Contamination. Int. J. Environ. Res. Public. Health 13. https://doi.org/10.3390/ijerph13060606

Bao, J., Chi, M., Benediktsson, J.A., 2013. Spectral Derivative Features for Classification of Hyperspectral Remote Sensing Images: Experimental Evaluation. IEEE J. Sel. Top. Appl. Earth Obs. Remote Sens. 6, 594601. https://doi.org/10.1109/JSTARS.2013.2237758 
522

523

524

525

526

527

528

529

530

531

532

533

534

535

536

537

538

539

540

541

542

543

544

545

546

547

548

549

550

551

552

553

554

555

556

557

558

559

560

561

562

Barceló, J., Poschenrieder, C., 1990. Plant water relations as affected by heavy metal stress: A review. J. Plant Nutr. 13, 1-37. https://doi.org/10.1080/01904169009364057

Bates, D., Mächler, M., Bolker, B., Walker, S., 2015. Fitting Linear MixedEffects Models Using Ime4. J. Stat. Softw. 67, 1-48. https://doi.org/10.18637/jss.v067.i01

Clevers, J.G.P.W., Kooistra, L., Salas, E.A.L., 2004. Study of heavy metal contamination in river floodplains using the red-edge position in spectroscopic data. Int. J. Remote Sens. 25, 3883-3895. https://doi.org/10.1080/01431160310001654473

Demetriades-Shah, T.H., Steven, M.D., Clark, J.A., 1990. High resolution derivative spectra in remote sensing. Remote Sens. Environ. 33, 5564. https://doi.org/10.1016/0034-4257(90)90055-Q

Doganlar, Z.B., Doganlar, O., Erdogan, S., Onal, Y., 2012. Heavy metal pollution and physiological changes in the leaves of some shrub, palm and tree species in urban areas of Adana, Turkey. Chem. Speciat. Bioavailab. 24, 65-78. https://doi.org/10.3184/095422912X13338055043100

European Commission, 2006. Commission staff working document Document accompanying the Communication from the Commission to the Council, The European Parliament, the European Economic and Social Committee and the Committee of the Regions - Thematic Strategy for Soil Protection - Impact assessment of the thematic strategy on soil protection $\{\operatorname{COM}(2006) 231$ final $\}$ SEC(2006)1165\}. Commission of the European Communities, Brussels.

Gallagher, F.J., Pechmann, I., Bogden, J.D., Grabosky, J., Weis, P., 2008. Soil metal concentrations and productivity of Betula populifolia (gray birch) as measured by field spectrometry and incremental annual growth in an abandoned urban Brownfield in New Jersey. Environ. Pollut. 156, 699-706. https://doi.org/10.1016/j.envpol.2008.06.013

Giulia, M., Lucia, S., Carmen, A., 2013. Heavy metal accumulation in leaves affects physiological performance and litter quality of Quercus ilex L. J. Plant Nutr. Soil Sci. 176, 776-784.

https://doi.org/10.1002/jpln.201200053

Gnyp, M.L., Miao, Y., Yuan, F., Ustin, S.L., Yu, K., Yao, Y., Huang, S., Bareth, G., 2014. Hyperspectral canopy sensing of paddy rice aboveground biomass at different growth stages. Field Crops Res. 155, 42-55. https://doi.org/10.1016/j.fcr.2013.09.023

Ho, Y.B., 1990. Ulva lactuca as bioindicator of metal contamination in intertidal waters in Hong Kong. Hydrobiologia 203, 73-81.

https://doi.org/10.1007/BF00005615 
563

564

565

566

567

568

569

570

571

572

573

574

575

576

577

578

579

580

581

582

583

584

585

586

587

588

589

590

591

592

593

594

595

596

597

598

599

600

601

602

603

604

605

Holt, E.A., Miller, S.W., 2010. Bioindicators: Using Organisms to Measure Environmental Impacts | Learn Science at Scitable. Nat. Educ. Knowl. 3,8 .

Horler, D.N.H., Barber, J., Barringer, A.R., 1980. Effects of heavy metals on the absorbance and reflectance spectra of plants. Int. J. Remote Sens. 1, 121-136. https://doi.org/10.1080/01431168008547550

Horler, D.N.H., Dockray, M., Barber, J., 1983. The red edge of plant leaf reflectance. Int. J. Remote Sens. 4, 273-288. https://doi.org/10.1080/01431168308948546

Huang, M., Zhu, H., Zhang, J., Tang, D., Han, X., Chen, L., Du, D., Yao, J., Chen, K., Sun, J., 2017. Toxic effects of cadmium on tall fescue and different responses of the photosynthetic activities in the photosystem electron donor and acceptor sides. Sci. Rep. 7. https://doi.org/10.1038/s41598-017-14718-w

Jin, J., Wang, Q., 2016. Hyperspectral indices based on first derivative spectra closely trace canopy transpiration in a desert plant. Ecol. Inform. 35, 1-8. https://doi.org/10.1016/j.ecoinf.2016.06.004

Kastori, R., Plesničar, M., Sakač, Z., Panković, D., Arsenijević-Maksimović, I., 1998. Effect of excess lead on sunflower growth and photosynthesis. J. Plant Nutr. 21, 75-85. https://doi.org/10.1080/01904169809365384

Khavanin Zadeh, A.R., Veroustraete, F., Buytaert, J.A.N., Dirckx, J., Samson, R., 2013. Assessing urban habitat quality using spectral characteristics of Tilia leaves. Environ. Pollut. 178, 7-14. https://doi.org/10.1016/j.envpol.2013.02.021

Kochubey, S.M., Kazantsev, T.A., 2012. Derivative vegetation indices as a new approach in remote sensing of vegetation. Front. Earth Sci. 6, 188-195. https://doi.org/10.1007/s11707-012-0325-z

Kooistra, L., Leuven, R.S.E.W., Wehrens, R., Nienhuis, P.H., Buydens, L.M.C., 2003. A comparison of methods to relate grass reflectance to soil metal contamination. Int. J. Remote Sens. 24, 4995-5010. https://doi.org/10.1080/0143116031000080769

Kooistra, L., Salas, E.A.L., Clevers, J.G.P.W., Wehrens, R., Leuven, R.S.E.W., Nienhuis, P.H., Buydens, L.M.C., 2004. Exploring field vegetation reflectance as an indicator of soil contamination in river floodplains. Environ. Pollut. 127, 281-290. https://doi.org/10.1016/S02697491(03)00266-5

Kovarik, W., 2005. Ethyl-leaded Gasoline: How a Classic Occupational Disease Became an International Public Health Disaster. Int. J. Occup. Environ. Health 11, 384-397. https://doi.org/10.1179/oeh.2005.11.4.384

Kumar, L., Schmidt, K., Dury, S., Skidmore, A., 2001. Imaging Spectrometry and Vegetation Science, in: van der Meer, F.D., De Jong, S.M. (Eds.), Imaging Spectrometry - Basic Principles and Prospective Applications, 
606

607

608

609

610

611

612

613

614

615

616

617

618

619

620

621

622

623

624

625

626

627

628

629

630

631

632

633

634

635

636

637

638

639

640

641

642

643

644

645

646

647

648

Remote Sensing and Digital Image Processing. Springer Netherlands, Dordrecht, pp. 111-155. https://doi.org/10.1007/978-0-306-475788_5

Lassalle, G., Credoz, A., Hédacq, R., Fabre, S., Dubucq, D., Elger, A., 2018. Assessing Soil Contamination Due to Oil and Gas Production Using Vegetation Hyperspectral Reflectance. Environ. Sci. Technol. 52, 1756-1764. https://doi.org/10.1021/acs.est.7b04618

Lenth, R.V., 2016. Least-Squares Means: The R Package Ismeans. J. Stat. Softw. 69, 1-33. https://doi.org/10.18637/jss.v069.i01

Li, X., Poon, C., Liu, P.S., 2001. Heavy metal contamination of urban soils and street dusts in Hong Kong. Appl. Geochem. 16, 1361-1368. https://doi.org/10.1016/S0883-2927(01)00045-2

Lichtenthaler, H.K., 1987. [34] Chlorophylls and carotenoids: Pigments of photosynthetic biomembranes, in: Methods in Enzymology, Plant Cell Membranes. Academic Press, pp. 350-382. https://doi.org/10.1016/0076-6879(87)48036-1

Liedekerke, M. van, Prokop, G., Rabl-Berger, S., Kibblewhite, M., Louwagie, G., European Commission, Joint Research Centre, Institute for Environment and Sustainability, 2014. Progress in the management of contaminated sites in Europe. Publications Office of the European Union, Luxembourg.

Manios, T., Stentiford, E.I., Millner, P.A., 2003. The effect of heavy metals accumulation on the chlorophyll concentration of Typha latifolia plants, growing in a substrate containing sewage sludge compost and watered with metaliferus water. Ecol. Eng. 20, 65-74.

https://doi.org/10.1016/S0925-8574(03)00004-1

MEF, 2007. Government Decree on the Assessment of Soil Contamination and Remediation Needs (No. 214/2007). Ministry of the Environment, Finland.

Nie, J., Liu, Y., Zeng, G., Zheng, B., Tan, X., Liu, H., Xie, J., Gan, C., Liu, W., 2016. Cadmium accumulation and tolerance of Macleaya cordata: a newly potential plant for sustainable phytoremediation in Cdcontaminated soil. Environ. Sci. Pollut. Res. 23, 10189-10199. https://doi.org/10.1007/s11356-016-6263-7

O'Connell, J.L., Byrd, K.B., Kelly, M., 2014. Remotely-Sensed Indicators of NRelated Biomass Allocation in Schoenoplectus acutus. PLoS ONE 9. https://doi.org/10.1371/journal.pone.0090870

Ouyang, H., Kong, X., He, W., Qin, N., He, Q., Wang, Y., Wang, R., Xu, F., 2012. Effects of five heavy metals at sub-lethal concentrations on the growth and photosynthesis of Chlorella vulgaris. Chin. Sci. Bull. 57, 3363-3370. https://doi.org/10.1007/s11434-012-5366-x

Panagos, P., Van Liedekerke, M., Yigini, Y., Montanarella, L., 2013. Contaminated Sites in Europe: Review of the Current Situation Based 
649

650

651

652

653

654

655

656

657

658

659

660

661

662

663

664

665

666

667

668

669

670

671

672

673

674

675

676

677

678

679

680

681

682

683

684

685

686

687

688

689

690

on Data Collected through a European Network. J. Environ. Public Health 2013, 11. https://doi.org/10.1155/2013/158764

Pandit, C.M., Filippelli, G.M., Li, L., 2010. Estimation of heavy-metal contamination in soil using reflectance spectroscopy and partial leastsquares regression. Int. J. Remote Sens. 31, 4111-4123. https://doi.org/10.1080/01431160903229200

Parmar, T.K., Rawtani, D., Agrawal, Y.K., 2016. Bioindicators: the natural indicator of environmental pollution. Front. Life Sci. 9, 110-118. https://doi.org/10.1080/21553769.2016.1162753

Poggio, L., Vrščaj, B., Schulin, R., Hepperle, E., Ajmone Marsan, F., 2009. Metals pollution and human bioaccessibility of topsoils in Grugliasco (Italy). Environ. Pollut. 157, 680-689. https://doi.org/10.1016/j.envpol.2008.08.009

Pourkhabbaz, A., Rastin, N., Olbrich, A., Langenfeld-Heyser, R., Polle, A., 2010. Influence of Environmental Pollution on Leaf Properties of Urban Plane Trees, Platanus orientalis L. Bull. Environ. Contam. Toxicol. 85, 251-255. https://doi.org/10.1007/s00128-010-0047-4

$\mathrm{Pu}, \mathrm{R} ., 2011$. Detecting and Mapping Invasive Plant Species by Using Hyperspectral Data, in: Thenkabail, P.S., Lyon, J.G., Huete, A. (Eds.), Hyperspectral Remote Sensing of Vegetation. CRC Press, Boca Raton, $\mathrm{FL}$, p. 447.

R Core Team, 2016. R: A language and environment for statistical computing. R Foundation for Statistical Computing, Vienna, Austria.

Rohart, F., Gautier, B., Singh, A., Cao, K.-A.L., 2017. mixOmics: an R package for 'omics feature selection and multiple data integration. bioRxiv 108597. https://doi.org/10.1101/108597

Rosipal, R., Krämer, N., 2006. Overview and Recent Advances in Partial Least Squares, in: Subspace, Latent Structure and Feature Selection, Lecture Notes in Computer Science. Springer, Berlin, Heidelberg, pp. 34-51. https://doi.org/10.1007/11752790_2

Rosso, P.H., Pushnik, J.C., Lay, M., Ustin, S.L., 2005. Reflectance properties and physiological responses of Salicornia virginica to heavy metal and petroleum contamination. Environ. Pollut. 137, 241-252.

https://doi.org/10.1016/j.envpol.2005.02.025

Rundquist, D.C., Han, L., Schalles, J.F., Peake, J.S., 1996. Remote Measurement of Algal Chlorophyll in Surface Waters: The Case for the First Derivative of Reflectance Near $690 \mathrm{~nm}$. Photogramm. Eng. Remote Sens. 62, 195-200.

Sawidis, T., Breuste, J., Mitrovic, M., Pavlovic, P., Tsigaridas, K., 2011. Trees as bioindicator of heavy metal pollution in three European cities.

Environ. Pollut. 159, 3560-3570.

https://doi.org/10.1016/j.envpol.2011.08.008 
691

692

693

694

695

696

697

698

699

700

701

702

703

704

705

706

707

708

709

710

711

712

713

714

715

716

717

718

719

720

721

722

723

724

725

726

727

728

729

Shen, J., Song, L., Müller, K., Hu, Y., Song, Y., Yu, W., Wang, H., Wu, J., 2016. Magnesium Alleviates Adverse Effects of Lead on Growth, Photosynthesis, and Ultrastructural Alterations of Torreya grandis Seedlings. Front. Plant Sci. 7. https://doi.org/10.3389/fpls.2016.01819

Shi, G., Cai, Q., 2009. Leaf plasticity in peanut (Arachis hypogaea L.) in response to heavy metal stress. Environ. Exp. Bot. 67, 112-117. https://doi.org/10.1016/j.envexpbot.2009.02.009

Shi, T., Chen, Y., Liu, Y., Wu, G., 2014. Visible and near-infrared reflectance spectroscopy-An alternative for monitoring soil contamination by heavy metals. J. Hazard. Mater. 265, 166-176. https://doi.org/10.1016/j.jhazmat.2013.11.059

Smith, K.L., Steven, M.D., Colls, J.J., 2004. Use of hyperspectral derivative ratios in the red-edge region to identify plant stress responses to gas leaks. Remote Sens. Environ. 92, 207-217. https://doi.org/10.1016/j.rse.2004.06.002

Tóth, G., Hermann, T., Da Silva, M.R., Montanarella, L., 2016. Heavy metals in agricultural soils of the European Union with implications for food safety. Environ. Int. 88, 299-309. https://doi.org/10.1016/j.envint.2015.12.017

Vince, T., Szabó, G., Csoma, Z., Sándor, G., Szabó, S., 2014. The spatial distribution pattern of heavy metal concentrations in urban soils - a study of anthropogenic effects in Berehove, Ukraine. Cent. Eur. J. Geosci. 6, 330-343. https://doi.org/10.2478/s13533-012-0179-7

Wang, F., Gao, J., Zha, Y., 2018. Hyperspectral sensing of heavy metals in soil and vegetation: Feasibility and challenges. ISPRS J. Photogramm. Remote Sens. 136, 73-84. https://doi.org/10.1016/j.isprsjprs.2017.12.003

Wei, B., Yang, L., 2010. A review of heavy metal contaminations in urban soils, urban road dusts and agricultural soils from China. Microchem. J. 94, 99-107. https://doi.org/10.1016/j.microc.2009.09.014

Wold, S., Sjöström, M., Eriksson, L., 2001. PLS-regression: a basic tool of chemometrics. Chemom. Intell. Lab. Syst., PLS Methods 58, 109-130. https://doi.org/10.1016/S0169-7439(01)00155-1

Wu, M., Wang, P.-Y., Sun, L.-G., Zhang, J.-J., Yu, J., Wang, Y.-W., Chen, G.$X ., 2014$. Alleviation of cadmium toxicity by cerium in rice seedlings is related to improved photosynthesis, elevated antioxidant enzymes and decreased oxidative stress. Plant Growth Regul. 74, 251-260. https://doi.org/10.1007/s10725-014-9916-x 


\section{Figure Captions}

Fig. 1. Boxplots with the leaf mass per area (LMA) differences between the binary classes ( $0=$ non-contaminated, $1=$ contaminated) of (a) Cd and (b) $\mathrm{Pb}$ contamination, as well as among multiple classes of (c) $\mathrm{Cd} \times \mathrm{Pb}$ and (d) $\mathrm{Pb}$ contamination. Significance levels are indicated according to the post-hoc Tukey's test of the applied mixed models.

Fig. 2. Boxplots with the leaf chlorophyll $a$ to $b$ ratio (Chla:Chlb) differences between the binary classes ( $0=$ non-contaminated, $1=$ contaminated $)$ of (a) $\mathrm{Cd}$ and (b) Pb contamination, as well as among multiple classes for (c) $\mathrm{Cd} \times \mathrm{Pb}$ and $(\mathrm{d}) \mathrm{Pb}$ contamination. Significance levels are indicated according to the post-hoc Tukey's test of the applied mixed models.

Fig. 3. Boxplots show the chlorophyll fluorescence Fv/Fm differences between the binary classes ( $0=$ non-contaminated, $1=$ contaminated $)$ of (a) Cd and (b) $\mathrm{Pb}$ contamination, as well as among multi-class classifications of (c) $\mathrm{Cd} \times \mathrm{Pb}$ and (d) $\mathrm{Pb}$ contamination. Significance levels are indicated according to the post-hoc Tukey's test of the applied mixed models.

Fig. 4. Leaf mean reflectance of the contaminated (1) and non-contaminated ( 0 ) trees subjected to (a) $\mathrm{Cd}$ and (b) $\mathrm{Pb}$, and their reflectance relative difference $((\mathrm{X} 1-\mathrm{X} 0) / \mathrm{X} 0)$ between the contaminated and non-contaminated leaves.

Fig. 5. Predicted versus observed classes for (a) Cd binary classification, (b) $\mathrm{Pb}$ binary classification, (c) $\mathrm{Cd} \times \mathrm{Pb}$ classification and (d) Pb multi-class classification. Here the first derivative reflectance data were used for (a), (b) and (c), the original reflectance were used for (d). Numbers indicate the confusion matrix of classification.

Fig. 6. The variable importance in projection (VIP) scores for the spectralbased PLS-DA models for binary classification for $\mathrm{Cd}$ and $\mathrm{Pb}$ contamination, and for multi-class classification of $\mathrm{Pb}$ and $\mathrm{CdxPb}$ contamination. VIP $\geqslant 0.8$ highlights the spectral bands contributing significantly to the PLS-DA models. 


\section{Tables}

Table 1. Measured soil heavy metal content and the threshold values for classification of contamination. $\mathrm{Cd}$ and $\mathrm{Pb}$ were the major contaminates in this study, and $\mathrm{Pb}$ was the only metal that reached the highline and thus $\mathrm{Pb}$ contamination was classified into three sub-classes.

\begin{tabular}{|c|c|c|c|c|c|c|}
\hline \multirow{2}{*}{ Metal } & \multirow{2}{*}{ Range (mg/kg) } & \multirow{2}{*}{ Threshold (mg/kg) } & \multicolumn{4}{|c|}{ Number of observations (n) } \\
\hline & & & Class 0 & Class $1 / \mathrm{Pb} 1$ & $\mathrm{~Pb} 2$ & $\mathrm{~Pb} 3$ \\
\hline Cd & $0-3.9$ & 1 & 294 & 39 & & \\
\hline $\mathrm{Pb}^{*}$ & $0-2170.8$ & 60 & 132 & $201 / 180$ & 17 & 4 \\
\hline Co & $0-15.9$ & 20 & 333 & 0 & & \\
\hline $\mathrm{Cr}$ & $0-120.9$ & 100 & 327 & 6 & & \\
\hline $\mathrm{Cu}$ & $0-159.1$ & 100 & 330 & 3 & & \\
\hline $\mathrm{Ni}$ & $0-76.8$ & 50 & 331 & 2 & & \\
\hline $\mathrm{Zn}$ & $10-265.8$ & 200 & 329 & 4 & & \\
\hline
\end{tabular}

*, Pb contamination sub-levels:

1) Low contamination $(60 \leq \mathrm{Pb}<200 \mathrm{mg} / \mathrm{kg})$;

2) Medium contamination $(200 \leq \mathrm{Pb}<750 \mathrm{mg} / \mathrm{kg}$ );

3) High contamination $(\mathrm{Pb} \geq 750 \mathrm{mg} / \mathrm{kg})$. 
Table 2. Results of mixed models for testing the effect of soil heavy metals on leaf functional traits, including the leaf mass per area (LMA), FV/Fm, total chlorophyll content (Chl) and Chla:Chlb ratio. Modelle, random effects were city and sites. Chlorophyll data were only available for a subset of the samples, where only $\mathrm{Cd}$ and $\mathrm{Pb}$ reached the thresholds of contamination.

\begin{tabular}{|c|c|c|c|c|c|}
\hline \multicolumn{4}{|c|}{ Mixed Model } & \multicolumn{2}{|c|}{ Tukey's Test Class $0-1$} \\
\hline Trait & Metal & F-value & $P$-value & Estimate & $P$-value \\
\hline \multirow[t]{6}{*}{ LMA } & $\mathrm{Cd}$ & 1.11 & 0.292 & 0.249 & 0.292 \\
\hline & $\mathrm{Cr}$ & 6.68 & 0.010 & -1.319 & 0.010 \\
\hline & $\mathrm{Cu}$ & 0.16 & 0.691 & 0.284 & 0.691 \\
\hline & $\mathrm{Ni}$ & 0.23 & 0.632 & 0.425 & 0.632 \\
\hline & $\mathrm{Pb}$ & 67.08 & $<0.001$ & 1.284 & $<0.001$ \\
\hline & $\mathrm{Zn}$ & 0.70 & 0.404 & 0.521 & 0.404 \\
\hline \multirow[t]{6}{*}{$\mathrm{Fv} / \mathrm{Fm}$} & $\mathrm{Cd}$ & 0.02 & 0.901 & -0.0013 & 0.901 \\
\hline & $\mathrm{Cr}$ & 0.01 & 0.905 & 0.0027 & 0.905 \\
\hline & $\mathrm{Cu}$ & 0.01 & 0.911 & 0.0034 & 0.911 \\
\hline & $\mathrm{Ni}$ & 0.08 & 0.772 & -0.0109 & 0.772 \\
\hline & $\mathrm{Pb}$ & 5.84 & 0.016 & -0.0162 & 0.016 \\
\hline & Zn & 0.08 & 0.784 & -0.0074 & 0.784 \\
\hline \multirow[t]{2}{*}{ Chl } & $\mathrm{Cd}$ & 2.31 & 0.138 & 18.091 & 0.138 \\
\hline & $\mathrm{Pb}$ & 6.78 & 0.013 & -9.238 & 0.013 \\
\hline \multirow[t]{2}{*}{ Chla:Chlb } & $\mathrm{Cd}$ & 0.45 & 0.509 & 0.181 & 0.509 \\
\hline & $\mathrm{Pb}$ & 23.58 & $<0.001$ & 0.331 & $<0.001$ \\
\hline
\end{tabular}


Table 3. Mixed models for testing the effect of multi-level $C d \times P b$ and $P b$ contamination on leaf functional traits, including the leaf mass per area (LMA), FV/Fm, total chlorophyll content (Chl) and Chla:Chlb ratio. The modeled random effects are city and site. Chlorophyll data were only available for a subset of the samples, where only Cd and $P b$ reached the threshold of contamination.

\begin{tabular}{|c|c|c|c|c|c|c|c|c|c|c|c|c|c|}
\hline \multirow{2}{*}{\multicolumn{4}{|c|}{ Mixed model }} & \multicolumn{10}{|c|}{ Tukey's Test } \\
\hline & & & & \multicolumn{2}{|c|}{ Class $0-1$} & \multicolumn{2}{|c|}{ Class $0-2$} & \multicolumn{2}{|c|}{ Class 0 - 3} & \multicolumn{2}{|c|}{ Class 1 - 2} & Class $1-3$ & Class $2-3$ \\
\hline Trait & Metal & F-value & $P$-value & estimate & $p$ & estimate & $p$ & estimate & $p$ & estimate & $p$ & estimate $p$ & estimate $P$ \\
\hline \multirow[t]{2}{*}{ LMA } & $\mathrm{Cd} \times \mathrm{Pb}$ & 23.74 & $<0.001$ & 0.025 & 1.000 & 1.256 & $<0.001$ & 1.722 & $<0.001$ & 1.231 & 0.006 & 1.6980 .001 & 0.4660 .246 \\
\hline & $\mathrm{Pb}$ & 26.29 & $<0.001$ & 1.21 & $<0.001$ & 1.831 & $<0.001$ & 2.444 & $<0.001$ & 0.621 & 0.104 & 1.2340 .104 & 0.6130 .731 \\
\hline \multirow[t]{2}{*}{$\mathrm{Fv} / \mathrm{fm}$} & $\mathrm{Cd} \times \mathrm{Pb}$ & 2.42 & 0.066 & -0.0211 & 0.661 & -0.0184 & 0.044 & -0.0143 & 0.713 & 0.0028 & 0.999 & 0.00690 .987 & 0.00410 .987 \\
\hline & $\mathrm{Pb}$ & 2.00 & 0.113 & -0.0168 & 0.070 & -0.0109 & 0.863 & -0.0106 & 0.980 & 0.0059 & 0.971 & 0.00620 .996 & 0.00031 .000 \\
\hline \multirow[t]{2}{*}{$\mathrm{Chl}$} & $\mathrm{Cd} \times \mathrm{Pb}$ & 5.86 & 0.006 & & & -10.275 & 0.014 & 12.558 & 0.495 & & & & 22.8340 .108 \\
\hline & $\mathrm{Pb}$ & 6.40 & 0.004 & -8.108 & 0.057 & -32.96 & 0.012 & & & -24.85 & 0.070 & & \\
\hline \multicolumn{2}{|c|}{ Chla:Chlb Cd×Pb } & 11.47 & $<0.001$ & & & 0.332 & $<0.001$ & 0.319 & 0.319 & & & & -0.0120 .998 \\
\hline & $\mathrm{Pb}$ & 12.01 & $<0.001$ & 0.323 & $<0.001$ & 0.495 & 0.072 & & & 0.172 & 0.709 & & \\
\hline
\end{tabular}




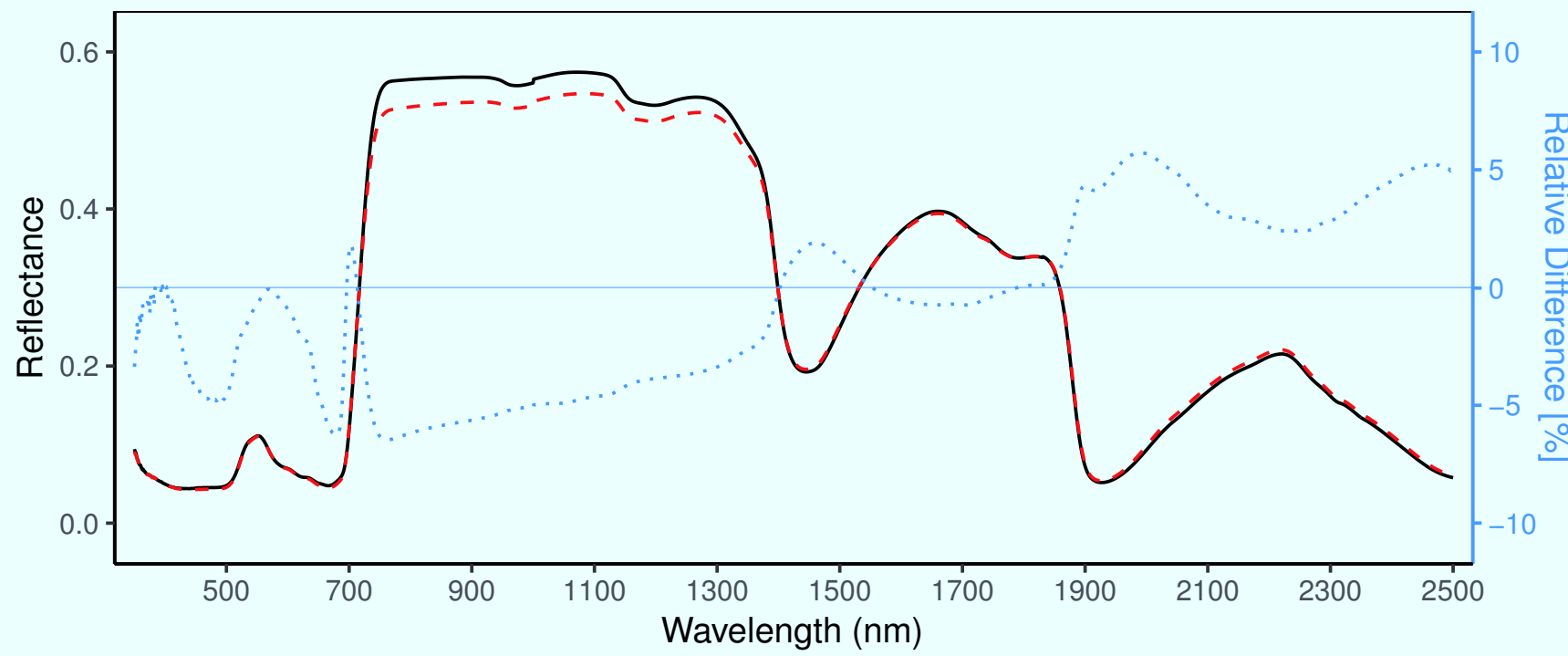

— $\mathrm{Pb} 0$ - $\mathrm{Pb} 1 \ldots$ Relative Difference

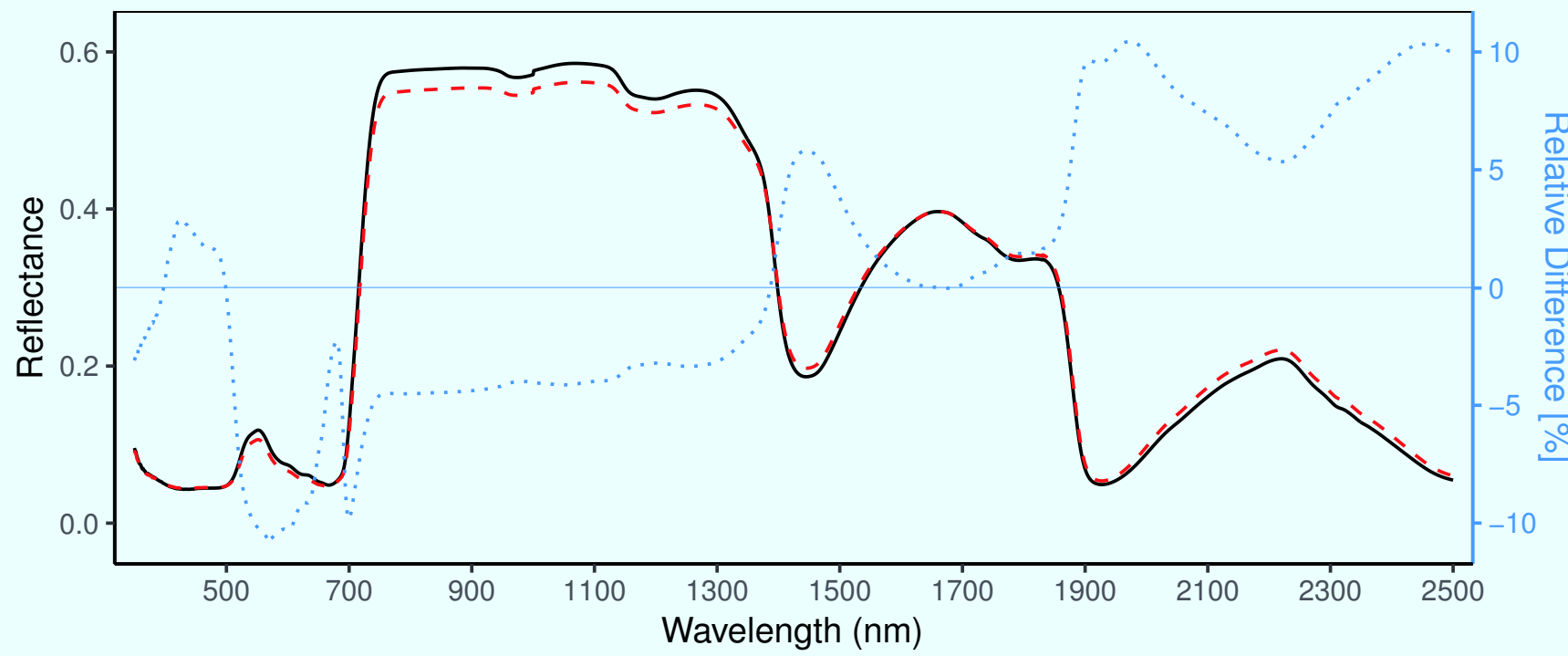




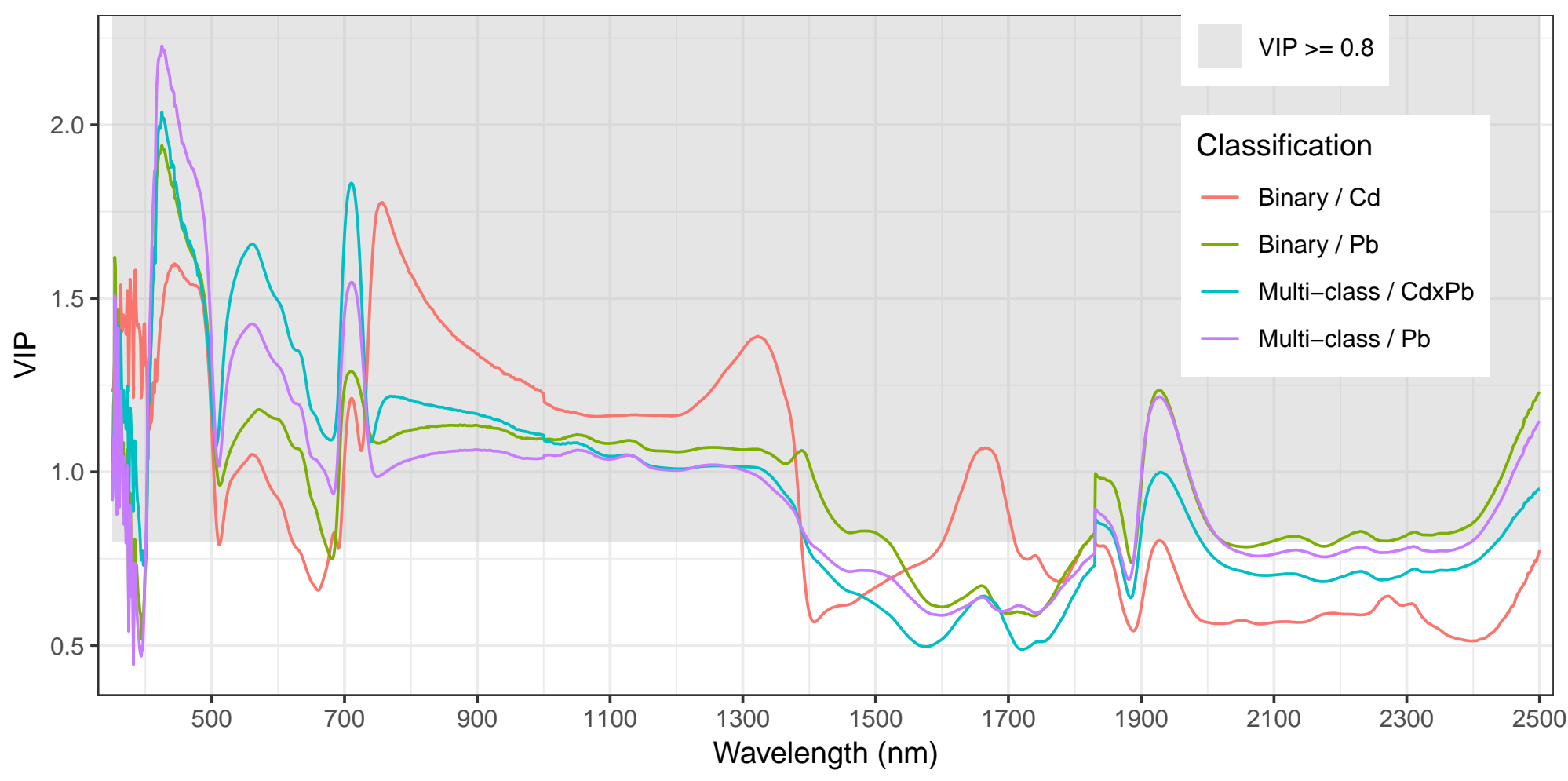




\section{Supplementary Material}

Title:

Vegetation reflectance spectroscopy for biomonitoring of heavy metal pollution in urban soils.

Authors:

Kang Yu, Maarten Van Geel, Tobias Ceulemans, Willem Geerts, Miguel Marcos Ramos, Nadine Sousa, Paula M.L. Castro, Pierre Kastendeuch, Georges Najjar, Thierry Ameglio, Jérôme Ngao, Marc Saudreau, Olivier Honnay, Ben Somers.

Table S1. Classification of samples into four contamination levels of heavy metals according to the two major contaminates $\mathrm{Cd}$ and $\mathrm{Pb}$ in this study.

\begin{tabular}{lcccc}
\hline & & & $\mathrm{Cd}$ & \\
\cline { 3 - 4 } Metal & Class & 0 & 1 & Total \\
\hline $\mathrm{Pb}$ & 0 & $\mathrm{CdxPb} 0$ & $\mathrm{CdxPb} 1$ & 132 \\
& & $(\mathrm{n}=121)$ & $(\mathrm{n}=11)$ & \\
& 1 & $\mathrm{CdxPb} 2$ & $\mathrm{CdxPb} 3$ & 201 \\
Total & & $(n=173)$ & $(\mathrm{n}=28)$ & 333 \\
\hline
\end{tabular}


Table S2. Results of mixed models for testing the effect of soil heavy metals on leaf functional traits, including the leaf mass per area (LMA), Fv/Fm, total chlorophyll content (Chl) and Chla:Chlb ratio. Modeled random effects were City, Site and Trunk Diameter. Chlorophyll data were only available for a subset of the samples, where only $\mathrm{Cd}$ and $\mathrm{Pb}$ reached the thresholds of contamination.

\begin{tabular}{|c|c|c|c|c|c|}
\hline \multicolumn{4}{|c|}{ Mixed Model } & \multicolumn{2}{|c|}{ Tukey's Test Class $0-1$} \\
\hline Trait & Metal & F-value & $P$-value & Estimate & $P$-value \\
\hline \multirow[t]{6}{*}{ LMA } & $\mathrm{Cd}$ & 1.114 & 0.292 & 0.249 & 0.292 \\
\hline & $\mathrm{Cr}$ & 6.676 & 0.01 & -1.319 & 0.01 \\
\hline & $\mathrm{Cu}$ & 0.158 & 0.691 & 0.284 & 0.691 \\
\hline & $\mathrm{Ni}$ & 0.23 & 0.632 & 0.425 & 0.632 \\
\hline & $\mathrm{Pb}$ & 67.079 & $<0.001$ & 1.284 & $<0.001$ \\
\hline & $\mathrm{Zn}$ & 0.699 & 0.404 & 0.521 & 0.404 \\
\hline \multirow[t]{6}{*}{$\mathrm{Fv} / \mathrm{Fm}$} & $\mathrm{Cd}$ & 0.016 & 0.901 & -0.001 & 0.901 \\
\hline & $\mathrm{Cr}$ & 0.014 & 0.905 & 0.003 & 0.905 \\
\hline & $\mathrm{Cu}$ & 0.012 & 0.911 & 0.003 & 0.911 \\
\hline & $\mathrm{Ni}$ & 0.084 & 0.772 & -0.011 & 0.772 \\
\hline & $\mathrm{Pb}$ & 5.842 & 0.016 & -0.016 & 0.016 \\
\hline & $\mathrm{Zn}$ & 0.075 & 0.784 & -0.007 & 0.784 \\
\hline \multirow[t]{2}{*}{$\mathrm{Chl}$} & $\mathrm{Cd}$ & 1.859 & 0.183 & 17.944 & 0.183 \\
\hline & $\mathrm{Pb}$ & 9.32 & 0.005 & -13.188 & 0.005 \\
\hline \multirow[t]{2}{*}{ Chla:Chlb } & $\mathrm{Cd}$ & 0.065 & 0.801 & 0.071 & 0.801 \\
\hline & $\mathrm{Pb}$ & 12.942 & 0.001 & 0.314 & 0.001 \\
\hline
\end{tabular}


Table S3. Mixed models for testing the effect of multi-level $\mathrm{Cd} \times \mathrm{Pb}$ and $\mathrm{Pb}$ contamination on leaf functional traits, including the leaf mass per area (LMA), Fv/Fm, total chlorophyll content (Chl) and Chla:Chlb ratio. The modeled random effects are City, Site and Trunk Diameter. Chlorophyll data were only available for a subset of the samples, where only $\mathrm{Cd}$ and $\mathrm{Pb}$ reached the threshold of contamination.

\begin{tabular}{|c|c|c|c|c|c|c|c|c|c|c|c|c|c|c|}
\hline \multirow[b]{3}{*}{ Trait } & \multirow{2}{*}{\multicolumn{3}{|c|}{ Mixed model }} & \multicolumn{11}{|c|}{ Tukey's Test } \\
\hline & & & & \multicolumn{2}{|c|}{ Class $0-1$} & \multicolumn{2}{|c|}{ Class $0-2$} & \multicolumn{2}{|c|}{ Class 0 - 3} & \multicolumn{2}{|c|}{ Class 1 - 2} & \multicolumn{2}{|c|}{ Class $1-3$} & Class $2-3$ \\
\hline & Metal & $F$-value & $P$-value & estimate & $p$ & estimate & $p$ & estimate & $p$ & estimate & $p$ & estimate & $p$ & estimate $P$ \\
\hline \multirow[t]{2}{*}{ LMA } & $\mathrm{Cd} \times \mathrm{Pb}$ & 23.741 & $<0.001$ & 0.025 & 1.000 & 1.256 & $<0.001$ & 1.722 & $<0.001$ & 1.231 & 0.006 & 1.698 & 0.001 & 0.4660 .246 \\
\hline & $\mathrm{Pb}$ & 26.290 & $<0.001$ & 1.210 & $<0.001$ & 1.831 & $<0.001$ & 2.444 & $<0.001$ & 0.621 & 0.104 & 1.234 & 0.104 & 0.6130 .731 \\
\hline \multirow[t]{2}{*}{$\mathrm{Fv} / \mathrm{fm}$} & $\mathrm{Cd} \times \mathrm{Pb}$ & 2.420 & 0.066 & -0.021 & 0.661 & -0.018 & 0.044 & -0.014 & 0.713 & 0.003 & 0.999 & 0.007 & 0.987 & 0.0040 .987 \\
\hline & $\mathrm{Pb}$ & 2.004 & 0.113 & -0.017 & 0.070 & -0.011 & 0.863 & -0.011 & 0.980 & 0.006 & 0.971 & 0.006 & 0.996 & 0.0001 .000 \\
\hline \multirow[t]{2}{*}{$\mathrm{Chl}$} & $\mathrm{Cd} \times \mathrm{Pb}$ & 7.103 & 0.003 & NA & NA & -14.226 & 0.005 & 8.608 & 0.743 & NA & NA & NA & NA & 22.8340 .132 \\
\hline & $\mathrm{Pb}$ & 7.659 & 0.002 & -12.058 & 0.018 & -36.911 & 0.009 & NA & NA & -24.852 & 0.089 & NA & NA & NA NA \\
\hline \multirow[t]{2}{*}{ Chla:Chlb } & $\mathrm{Cd} \times \mathrm{Pb}$ & 6.265 & 0.006 & NA & NA & 0.315 & 0.004 & 0.297 & 0.463 & NA & NA & NA & NA & -0.0180 .997 \\
\hline & $\mathrm{Pb}$ & 6.679 & 0.004 & 0.302 & 0.006 & 0.483 & 0.124 & NA & NA & 0.181 & 0.729 & NA & NA & NA \\
\hline
\end{tabular}

NA, not applicable. 
Table S4. PLS-DA model calibration accuracies for the binary classification of $\mathrm{Cd}$ and $\mathrm{Pb}$ contamination and for multi-class classification of $\mathrm{Cd} \times \mathrm{Pb}$ interactions and four-level $\mathrm{Pb}$ contamination.

\begin{tabular}{llrrrrr}
\hline Metal & Spectra* & Components & Producer Accuracy & User Accuracy & Accuracy & Kappa \\
\hline Binary & & & & & & \\
$\mathrm{Cd}$ & ASD & 5 & $74.36 \%$ & $45.31 \%$ & $86.49 \%$ & 0.49 \\
& ASD.cr & 4 & $82.05 \%$ & $41.03 \%$ & $84.08 \%$ & 0.46 \\
& ASD.d1 & 2 & $76.92 \%$ & $42.86 \%$ & $85.29 \%$ & 0.47 \\
& ASD.snv & 2 & $76.92 \%$ & $42.86 \%$ & $85.29 \%$ & 0.47 \\
$\mathrm{~Pb}$ & ASD & 2 & $64.18 \%$ & $90.85 \%$ & $74.47 \%$ & 0.50 \\
& ASD.cr & 5 & $65.17 \%$ & $86.18 \%$ & $72.67 \%$ & 0.46 \\
& ASD.d1 & 4 & $71.14 \%$ & $89.94 \%$ & $77.78 \%$ & 0.56 \\
& ASD.snv & 5 & $64.68 \%$ & $87.25 \%$ & $72.97 \%$ & 0.47 \\
Multi-class & & & & & & \\
$\mathrm{CdxPb}$ & ASD & 4 & NA\% & NA\% & $43.24 \%$ & 0.24 \\
& ASD.cr & 8 & NA\% & NA\% & $62.16 \%$ & 0.44 \\
& ASD.d1 & 5 & NA\% & NA\% & $66.07 \%$ & 0.49 \\
& ASD.snv & 4 & NA\% & NA\% & $50.15 \%$ & 0.27 \\
$\mathrm{~Pb}$ & ASD & 3 & NA\% & NA\% & $51.95 \%$ & 0.29 \\
& ASD.cr & 8 & NA\% & NA\% & $52.85 \%$ & 0.31 \\
& ASD.d1 & 8 & NA\% & NA\% & $63.96 \%$ & 0.43 \\
& ASD.snv & 6 & NA\% & NA\% & $54.05 \%$ & 0.29 \\
\hline
\end{tabular}

${ }^{*} \mathrm{cr}$, continuum removal; d1, first derivatives; snv, standard normal variate. 
Table S5. Validation of the PLS-DA models calibrated with the full wavebands and VIP ( $\geqslant 0.8)$ bands for the binary classification of $\mathrm{Cd}$ and Pb contamination and for multi-class classification of $\mathrm{CdxPb}$ and $\mathrm{Pb}$ contamination. Model training used 2/3 of the observations ( $\mathrm{n}=215$ ), and the remaining $1 / 3$ of the observations ( $n=118$ ) were used for testing model accuracies.

\begin{tabular}{|c|c|c|c|c|c|c|c|c|c|c|c|}
\hline \multirow[b]{2}{*}{ Metal } & \multirow[b]{2}{*}{ Spectra* } & \multicolumn{5}{|c|}{ Full spectrum } & \multicolumn{5}{|c|}{ VIP bands } \\
\hline & & Components & $\begin{array}{l}\text { Producer } \\
\text { Accuracy }\end{array}$ & $\begin{array}{c}\text { User } \\
\text { Accuracy }\end{array}$ & Accuracy & Карра & Components & $\begin{array}{l}\text { Producer } \\
\text { Accuracy }\end{array}$ & $\begin{array}{c}\text { User } \\
\text { Accuracy }\end{array}$ & Accuracy & Карра \\
\hline \multicolumn{12}{|l|}{ Binary } \\
\hline \multirow[t]{4}{*}{$\overline{C d}$} & ASD & 8 & $13.33 \%$ & $100.00 \%$ & $88.98 \%$ & 0.21 & 8 & $13.33 \%$ & $100.00 \%$ & $88.98 \%$ & 0.21 \\
\hline & ASD.cr & 3 & $66.67 \%$ & $47.62 \%$ & $86.44 \%$ & 0.48 & 3 & $66.67 \%$ & $38.46 \%$ & $82.20 \%$ & 0.39 \\
\hline & ASD.d1 & 6 & $26.67 \%$ & $80.00 \%$ & $89.83 \%$ & 0.36 & 6 & $26.67 \%$ & $80.00 \%$ & $89.83 \%$ & 0.36 \\
\hline & ASD.snv & 8 & $13.33 \%$ & $66.67 \%$ & $88.14 \%$ & 0.19 & 8 & $6.67 \%$ & $33.33 \%$ & $86.44 \%$ & 0.07 \\
\hline \multirow[t]{4}{*}{$\mathrm{Pb}$} & ASD & 8 & $74.55 \%$ & $77.36 \%$ & $77.97 \%$ & 0.56 & 8 & $83.64 \%$ & $79.31 \%$ & $82.20 \%$ & 0.64 \\
\hline & ASD.cr & 10 & $74.55 \%$ & $83.67 \%$ & $81.36 \%$ & 0.62 & 10 & $76.36 \%$ & $85.71 \%$ & $83.05 \%$ & 0.66 \\
\hline & ASD.d1 & 6 & $80.00 \%$ & $77.19 \%$ & $79.66 \%$ & 0.59 & 6 & $89.09 \%$ & $77.78 \%$ & $83.05 \%$ & 0.66 \\
\hline & ASD.snv & 10 & $70.91 \%$ & $82.98 \%$ & $79.66 \%$ & 0.59 & 10 & $69.09 \%$ & $79.17 \%$ & $77.12 \%$ & 0.54 \\
\hline \multicolumn{12}{|c|}{ Multi-class } \\
\hline \multirow[t]{4}{*}{$\mathrm{CdxPb}$} & ASD & 9 & NA\% & NA\% & $68.64 \%$ & 0.44 & 9 & NA\% & NA\% & $70.34 \%$ & 0.47 \\
\hline & ASD.cr & 5 & NA\% & NA\% & $66.10 \%$ & 0.41 & 4 & NA\% & NA\% & $66.10 \%$ & 0.40 \\
\hline & ASD.d1 & 4 & NA\% & NA\% & $65.25 \%$ & 0.45 & 4 & NA\% & NA\% & $66.10 \%$ & 0.46 \\
\hline & ASD.snv & 6 & NA\% & NA\% & $68.64 \%$ & 0.48 & 6 & NA\% & NA\% & $68.64 \%$ & 0.48 \\
\hline \multirow[t]{4}{*}{$\mathrm{Pb}$} & ASD & 9 & NA\% & NA\% & $75.42 \%$ & 0.52 & 9 & NA\% & NA\% & $75.42 \%$ & 0.52 \\
\hline & ASD.cr & 3 & NA\% & NA\% & $72.88 \%$ & 0.49 & 3 & NA\% & NA\% & $74.58 \%$ & 0.52 \\
\hline & ASD.d1 & 9 & NA\% & NA\% & 78.81\% & 0.59 & 9 & NA\% & NA\% & $79.66 \%$ & 0.61 \\
\hline & ASD.snv & 10 & NA\% & NA\% & $64.41 \%$ & 0.37 & 10 & NA\% & NA\% & $62.71 \%$ & 0.35 \\
\hline
\end{tabular}

${ }^{*} \mathrm{cr}$, continuum removal; d1, first derivatives; snv, standard normal variate. 
Table S6. Classification accuracies of PLS-DA model calibration using the original and preprocessed reflectance data with a fixed $(n=5)$ and the optimized number of components determined by cross-validation. Producer and user accuracies are not valid for the cases of absent prediction of individual classes.

\begin{tabular}{|c|c|c|c|c|c|c|c|}
\hline \multirow[b]{2}{*}{ Classification } & \multirow[b]{2}{*}{ Metal } & \multirow[b]{2}{*}{ Spectra } & \multirow[b]{2}{*}{ Components } & \multicolumn{3}{|c|}{ Accuracy } & \multirow[b]{2}{*}{ Карра } \\
\hline & & & & Producer & User & Total & \\
\hline Binary & $\mathrm{Cd}$ & ASD & 9 & $23.08 \%$ & $69.23 \%$ & $89.79 \%$ & 0.31 \\
\hline Binary & $\mathrm{Cd}$ & ASD & 5 & $10.26 \%$ & $57.14 \%$ & $88.59 \%$ & 0.14 \\
\hline Binary & $\mathrm{Cd}$ & ASD.cr & 5 & $12.82 \%$ & $71.43 \%$ & $89.19 \%$ & 0.19 \\
\hline Binary & $\mathrm{Cd}$ & ASD.cr & 4 & $82.05 \%$ & $41.03 \%$ & $84.08 \%$ & 0.46 \\
\hline Binary & $\mathrm{Cd}$ & ASD.d1 & 2 & $76.92 \%$ & $42.86 \%$ & $85.29 \%$ & 0.47 \\
\hline Binary & $\mathrm{Cd}$ & ASD.d1 & 5 & $38.46 \%$ & $68.18 \%$ & $90.69 \%$ & 0.44 \\
\hline Binary & $\mathrm{Cd}$ & ASD.snv & 2 & $76.92 \%$ & $42.86 \%$ & $85.29 \%$ & 0.47 \\
\hline Binary & $\mathrm{Cd}$ & ASD.snv & 5 & $12.82 \%$ & $62.50 \%$ & $88.89 \%$ & 0.18 \\
\hline Binary & $\mathrm{Pb}$ & ASD & 5 & $85.07 \%$ & $84.24 \%$ & $81.38 \%$ & 0.61 \\
\hline Binary & $\mathrm{Pb}$ & ASD & 7 & $87.06 \%$ & $86.21 \%$ & $83.78 \%$ & 0.66 \\
\hline Binary & $\mathrm{Pb}$ & ASD.cr & 4 & $85.57 \%$ & $85.57 \%$ & $82.58 \%$ & 0.64 \\
\hline Binary & $\mathrm{Pb}$ & ASD.cr & 5 & $65.17 \%$ & $86.18 \%$ & $72.67 \%$ & 0.46 \\
\hline Binary & $\mathrm{Pb}$ & ASD.d1 & 5 & $91.54 \%$ & $88.04 \%$ & $87.39 \%$ & 0.73 \\
\hline Binary & $\mathrm{Pb}$ & ASD.d1 & 4 & $71.14 \%$ & $89.94 \%$ & $77.78 \%$ & 0.56 \\
\hline Binary & $\mathrm{Pb}$ & ASD.snv & 9 & $82.59 \%$ & $87.83 \%$ & $82.58 \%$ & 0.64 \\
\hline Binary & $\mathrm{Pb}$ & ASD.snv & 5 & $64.68 \%$ & $87.25 \%$ & $72.97 \%$ & 0.47 \\
\hline Multi-class & $\mathrm{Cd} \times \mathrm{Pb}$ & ASD & 5 & NA\% & NA\% & $68.64 \%$ & 0.44 \\
\hline Multi-class & $\mathrm{Cd} \times \mathrm{Pb}$ & ASD & 4 & NA\% & NA\% & $43.24 \%$ & 0.24 \\
\hline Multi-class & $\mathrm{Cd} \times \mathrm{Pb}$ & ASD.cr & 8 & NA\% & NA\% & $62.16 \%$ & 0.44 \\
\hline Multi-class & $\mathrm{Cd} \times \mathrm{Pb}$ & ASD.cr & 5 & NA\% & NA\% & $71.77 \%$ & 0.48 \\
\hline Multi-class & $\mathrm{Cd} \times \mathrm{Pb}$ & ASD.d1 & 9 & NA\% & NA\% & $80.78 \%$ & 0.65 \\
\hline Multi-class & $\mathrm{Cd} \times \mathrm{Pb}$ & ASD.d1 & 5 & NA\% & NA\% & $66.07 \%$ & 0.49 \\
\hline Multi-class & $\mathrm{Cd} \times \mathrm{Pb}$ & ASD.snv & 4 & NA\% & NA\% & $50.15 \%$ & 0.27 \\
\hline Multi-class & $\mathrm{Cd} \times \mathrm{Pb}$ & ASD.snv & 5 & NA\% & NA\% & $66.37 \%$ & 0.39 \\
\hline Multi-class & $\mathrm{Pb}$ & ASD & 5 & NA\% & NA\% & $71.19 \%$ & 0.46 \\
\hline Multi-class & $\mathrm{Pb}$ & ASD & 6 & NA\% & NA\% & $77.48 \%$ & 0.56 \\
\hline Multi-class & $\mathrm{Pb}$ & ASD.cr & 8 & NA\% & NA\% & $52.85 \%$ & 0.31 \\
\hline Multi-class & $\mathrm{Pb}$ & ASD.cr & 5 & NA\% & NA\% & $75.38 \%$ & 0.52 \\
\hline Multi-class & $\mathrm{Pb}$ & ASD.d1 & 8 & NA\% & NA\% & $63.96 \%$ & 0.43 \\
\hline Multi-class & $\mathrm{Pb}$ & ASD.d1 & 5 & NA\% & NA\% & $79.28 \%$ & 0.6 \\
\hline Multi-class & $\mathrm{Pb}$ & ASD.snv & 6 & NA\% & NA\% & $54.05 \%$ & 0.29 \\
\hline Multi-class & $\mathrm{Pb}$ & ASD.snv & 5 & NA\% & NA\% & $71.77 \%$ & 0.45 \\
\hline
\end{tabular}


Table S7. Classification accuracies of PLS-DA model validation by dividing the entire dataset to train $(n=215)$ and test $(n=118)$ sub sets and applying onto the original and preprocessed reflectance data with a fixed (5) and the optimized number of components determined by crossvalidation. Producer and user accuracies are not valid for the cases of absent prediction of individual classes.

\begin{tabular}{|c|c|c|c|c|c|c|c|}
\hline \multirow[b]{2}{*}{ Classification } & \multirow[b]{2}{*}{ Metal } & \multirow[b]{2}{*}{ Spectra } & \multirow[b]{2}{*}{ Components } & \multicolumn{3}{|c|}{ Accuracy } & \multirow[b]{2}{*}{ Карра } \\
\hline & & & & Producer & User & Total & \\
\hline Binary & $\mathrm{Cd}$ & ASD & 8 & $13.33 \%$ & $100.00 \%$ & $88.98 \%$ & 0.21 \\
\hline Binary & $\mathrm{Cd}$ & ASD & 5 & $6.67 \%$ & $100.00 \%$ & $88.14 \%$ & 0.11 \\
\hline Binary & $\mathrm{Cd}$ & ASD.cr & 3 & $66.67 \%$ & $47.62 \%$ & $86.44 \%$ & 0.48 \\
\hline Binary & $\mathrm{Cd}$ & ASD.cr & 5 & $6.67 \%$ & $100.00 \%$ & $88.14 \%$ & 0.11 \\
\hline Binary & $\mathrm{Cd}$ & ASD.d1 & 6 & $26.67 \%$ & $80.00 \%$ & $89.83 \%$ & 0.36 \\
\hline Binary & $\mathrm{Cd}$ & ASD.d1 & 5 & $26.67 \%$ & $100.00 \%$ & $90.68 \%$ & 0.39 \\
\hline Binary & $\mathrm{Cd}$ & ASD.snv & 8 & $13.33 \%$ & $66.67 \%$ & $88.14 \%$ & 0.19 \\
\hline Binary & $\mathrm{Cd}$ & ASD.snv & 5 & $13.33 \%$ & $100.00 \%$ & $88.98 \%$ & 0.21 \\
\hline Binary & $\mathrm{Pb}$ & ASD & 8 & $74.55 \%$ & $77.36 \%$ & $77.97 \%$ & 0.56 \\
\hline Binary & $\mathrm{Pb}$ & ASD & 5 & $87.27 \%$ & $75.00 \%$ & $80.51 \%$ & 0.61 \\
\hline Binary & $\mathrm{Pb}$ & ASD.cr & 10 & $74.55 \%$ & $83.67 \%$ & $81.36 \%$ & 0.62 \\
\hline Binary & $\mathrm{Pb}$ & ASD.cr & 5 & $87.27 \%$ & $72.73 \%$ & $78.81 \%$ & 0.58 \\
\hline Binary & $\mathrm{Pb}$ & ASD.d1 & 6 & $80.00 \%$ & $77.19 \%$ & $79.66 \%$ & 0.59 \\
\hline Binary & $\mathrm{Pb}$ & ASD.d1 & 5 & $83.64 \%$ & $80.70 \%$ & $83.05 \%$ & 0.66 \\
\hline Binary & $\mathrm{Pb}$ & ASD.snv & 10 & $70.91 \%$ & $82.98 \%$ & $79.66 \%$ & 0.59 \\
\hline Binary & $\mathrm{Pb}$ & ASD.snv & 5 & $80.00 \%$ & $72.13 \%$ & $76.27 \%$ & 0.53 \\
\hline Multi-class & $\mathrm{Cd} \times \mathrm{Pb}$ & ASD & 9 & NA\% & NA\% & $68.64 \%$ & 0.44 \\
\hline Multi-class & $\mathrm{Cd} \times \mathrm{Pb}$ & ASD & 5 & NA\% & NA\% & $68.64 \%$ & 0.44 \\
\hline Multi-class & $\mathrm{Cd} \times \mathrm{Pb}$ & ASD.cr & 5 & NA\% & NA\% & $66.10 \%$ & 0.41 \\
\hline Multi-class & $\mathrm{Cd} \times \mathrm{Pb}$ & ASD.cr & 4 & NA\% & NA\% & $65.25 \%$ & 0.39 \\
\hline Multi-class & $\mathrm{Cd} \times \mathrm{Pb}$ & ASD.d1 & 4 & NA\% & NA\% & $65.25 \%$ & 0.45 \\
\hline Multi-class & $\mathrm{Cd} \times \mathrm{Pb}$ & ASD.d1 & 5 & NA\% & NA\% & $70.34 \%$ & 0.47 \\
\hline Multi-class & $\mathrm{Cd} \times \mathrm{Pb}$ & ASD.snv & 6 & NA\% & NA\% & $68.64 \%$ & 0.48 \\
\hline Multi-class & $\mathrm{Cd} \times \mathrm{Pb}$ & ASD.snv & 5 & NA\% & NA\% & $61.02 \%$ & 0.32 \\
\hline Multi-class & $\mathrm{Pb}$ & ASD & 9 & NA\% & NA\% & $75.42 \%$ & 0.52 \\
\hline Multi-class & $\mathrm{Pb}$ & ASD & 5 & NA\% & NA\% & $72.03 \%$ & 0.48 \\
\hline Multi-class & $\mathrm{Pb}$ & ASD.cr & 3 & NA\% & NA\% & $72.88 \%$ & 0.49 \\
\hline Multi-class & $\mathrm{Pb}$ & ASD.cr & 5 & NA\% & NA\% & $73.73 \%$ & 0.51 \\
\hline Multi-class & $\mathrm{Pb}$ & ASD.d1 & 9 & NA\% & NA\% & $78.81 \%$ & 0.59 \\
\hline Multi-class & $\mathrm{Pb}$ & ASD.d1 & 5 & NA\% & NA\% & $77.97 \%$ & 0.58 \\
\hline Multi-class & $\mathrm{Pb}$ & ASD.snv & 10 & NA\% & NA\% & $64.41 \%$ & 0.37 \\
\hline Multi-class & $\mathrm{Pb}$ & ASD.snv & 5 & NA\% & NA\% & $73.73 \%$ & 0.5 \\
\hline
\end{tabular}


Table S8. Classification accuracies of VIP-based PLS-DA model validation by dividing the entire dataset to train $(n=215)$ and test $(n=118)$ sub sets and applying onto the original and preprocessed reflectance data with a fixed (5) and the optimized number of components determined by crossvalidation. Producer and user accuracies are not valid for the cases of absent prediction of individual classes.

\begin{tabular}{|c|c|c|c|c|c|c|c|}
\hline \multirow[b]{2}{*}{ Classification } & \multirow[b]{2}{*}{ Metal } & \multirow[b]{2}{*}{ Spectra } & \multirow[b]{2}{*}{ Components } & \multicolumn{3}{|c|}{ Accuracy } & \multirow[b]{2}{*}{ Карра } \\
\hline & & & & Producer & User & Total & \\
\hline Binary & $\mathrm{Cd}$ & ASD & 5 & $6.67 \%$ & $100.00 \%$ & $88.14 \%$ & 0.11 \\
\hline Binary & $\mathrm{Cd}$ & ASD & 8 & $13.33 \%$ & $100.00 \%$ & $88.98 \%$ & 0.21 \\
\hline Binary & $\mathrm{Cd}$ & ASD.cr & 5 & $6.67 \%$ & $100.00 \%$ & $88.14 \%$ & 0.11 \\
\hline Binary & $\mathrm{Cd}$ & ASD.cr & 3 & $66.67 \%$ & $38.46 \%$ & $82.20 \%$ & 0.39 \\
\hline Binary & $\mathrm{Cd}$ & ASD.d1 & 5 & $20.00 \%$ & $100.00 \%$ & $89.83 \%$ & 0.3 \\
\hline Binary & $\mathrm{Cd}$ & ASD.d1 & 6 & $26.67 \%$ & $80.00 \%$ & $89.83 \%$ & 0.36 \\
\hline Binary & $\mathrm{Cd}$ & ASD.snv & 5 & $13.33 \%$ & $100.00 \%$ & $88.98 \%$ & 0.21 \\
\hline Binary & $\mathrm{Cd}$ & ASD.snv & 8 & $6.67 \%$ & $33.33 \%$ & $86.44 \%$ & 0.07 \\
\hline Binary & $\mathrm{Pb}$ & ASD & 5 & $83.64 \%$ & $73.02 \%$ & $77.97 \%$ & 0.56 \\
\hline Binary & $\mathrm{Pb}$ & ASD & 8 & $83.64 \%$ & $79.31 \%$ & $82.20 \%$ & 0.64 \\
\hline Binary & $\mathrm{Pb}$ & ASD.cr & 5 & $83.64 \%$ & $74.19 \%$ & $78.81 \%$ & 0.58 \\
\hline Binary & $\mathrm{Pb}$ & ASD.cr & 10 & $76.36 \%$ & $85.71 \%$ & $83.05 \%$ & 0.66 \\
\hline Binary & $\mathrm{Pb}$ & ASD.d1 & 5 & $90.91 \%$ & $80.65 \%$ & $85.59 \%$ & 0.71 \\
\hline Binary & $\mathrm{Pb}$ & ASD.d1 & 6 & $89.09 \%$ & $77.78 \%$ & $83.05 \%$ & 0.66 \\
\hline Binary & $\mathrm{Pb}$ & ASD.snv & 5 & $80.00 \%$ & $70.97 \%$ & $75.42 \%$ & 0.51 \\
\hline Binary & $\mathrm{Pb}$ & ASD.snv & 10 & $69.09 \%$ & $79.17 \%$ & $77.12 \%$ & 0.54 \\
\hline Multi-class & $\mathrm{Cd} \times \mathrm{Pb}$ & ASD & 5 & NA\% & NA\% & $67.80 \%$ & 0.43 \\
\hline Multi-class & $\mathrm{Cd} \times \mathrm{Pb}$ & ASD & 9 & NA\% & NA\% & $70.34 \%$ & 0.47 \\
\hline Multi-class & $\mathrm{Cd} \times \mathrm{Pb}$ & ASD.cr & 5 & NA\% & NA\% & $66.10 \%$ & 0.41 \\
\hline Multi-class & $\mathrm{Cd} \times \mathrm{Pb}$ & ASD.cr & 4 & NA\% & NA\% & $66.10 \%$ & 0.4 \\
\hline Multi-class & $\mathrm{Cd} \times \mathrm{Pb}$ & ASD.d1 & 5 & NA\% & NA\% & $68.64 \%$ & 0.44 \\
\hline Multi-class & $\mathrm{Cd} \times \mathrm{Pb}$ & ASD.d1 & 4 & NA\% & NA\% & $66.10 \%$ & 0.46 \\
\hline Multi-class & $\mathrm{Cd} \times \mathrm{Pb}$ & ASD.snv & 5 & NA\% & NA\% & $62.71 \%$ & 0.36 \\
\hline Multi-class & $\mathrm{Cd} \times \mathrm{Pb}$ & ASD.snv & 6 & NA\% & NA\% & $68.64 \%$ & 0.48 \\
\hline Multi-class & $\mathrm{Pb}$ & ASD & 5 & NA\% & NA\% & $76.27 \%$ & 0.55 \\
\hline Multi-class & $\mathrm{Pb}$ & ASD & 9 & NA\% & NA\% & $75.42 \%$ & 0.52 \\
\hline Multi-class & $\mathrm{Pb}$ & ASD.cr & 5 & NA\% & NA\% & $72.88 \%$ & 0.49 \\
\hline Multi-class & $\mathrm{Pb}$ & ASD.cr & 3 & NA\% & NA\% & $74.58 \%$ & 0.52 \\
\hline Multi-class & $\mathrm{Pb}$ & ASD.d1 & 5 & NA\% & NA\% & $77.97 \%$ & 0.58 \\
\hline Multi-class & $\mathrm{Pb}$ & ASD.d1 & 9 & NA\% & NA\% & $79.66 \%$ & 0.61 \\
\hline Multi-class & $\mathrm{Pb}$ & ASD.snv & 5 & NA\% & NA\% & $71.19 \%$ & 0.46 \\
\hline Multi-class & $\mathrm{Pb}$ & ASD.snv & 10 & NA\% & NA\% & $62.71 \%$ & 0.35 \\
\hline
\end{tabular}




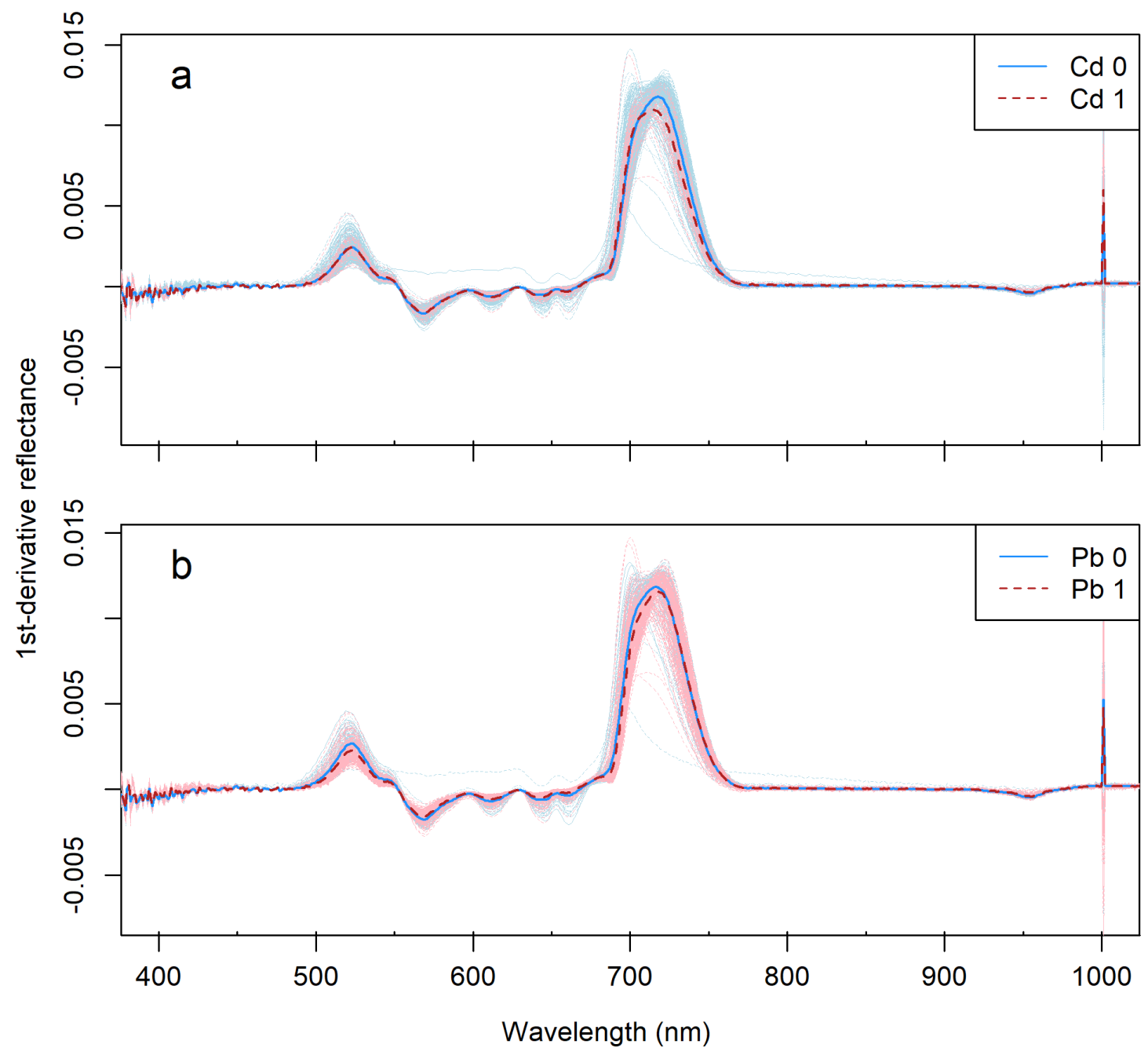

Fig. S1. First derivative reflectance of the leaves of the non-contaminated as compared with the contaminated soils by (a) Cd and (b) Pb. 

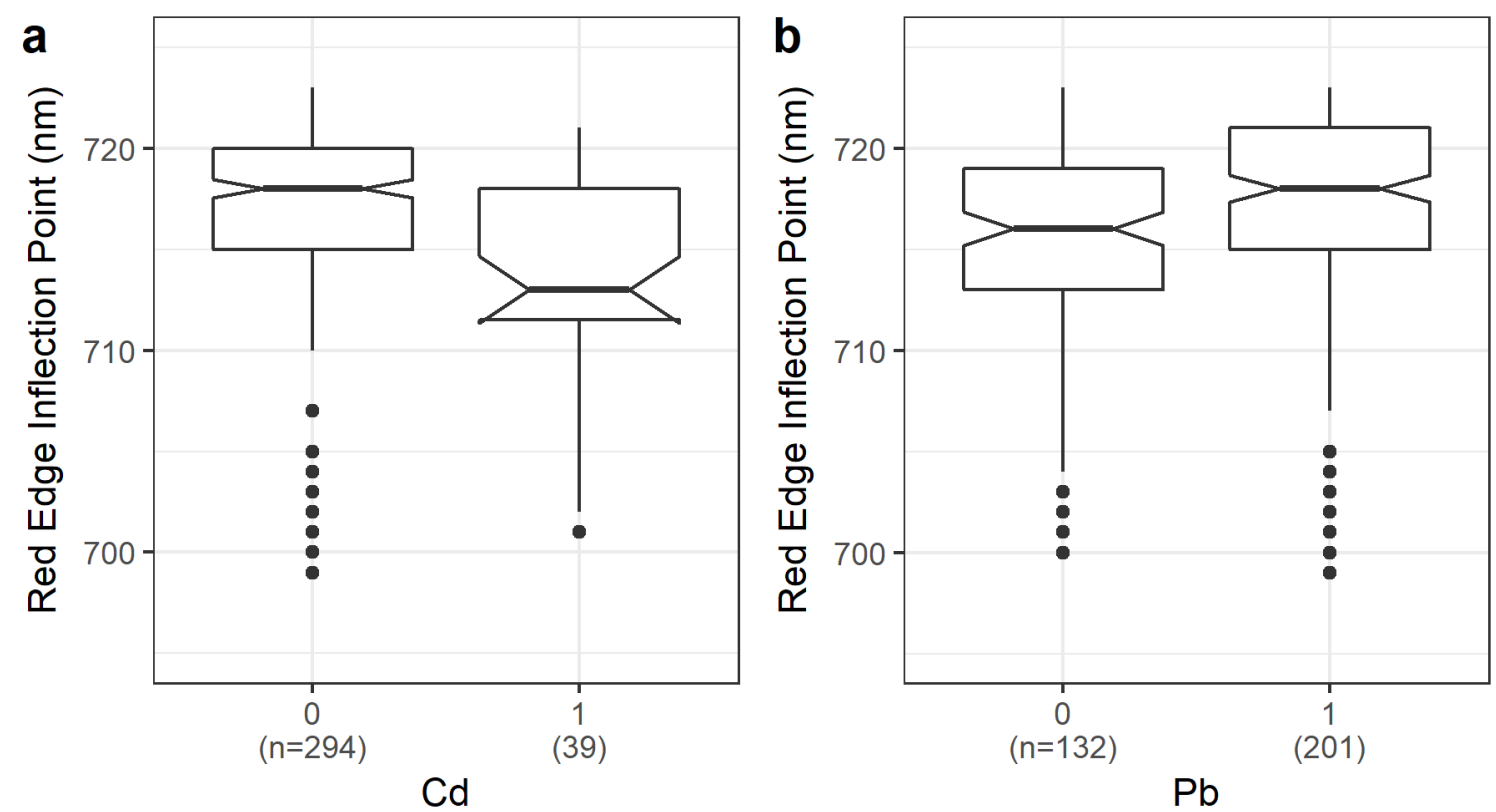

Fig. S2. Red-edge inflection points (REIP) extracted from the first derivative reflectance show the differences between the contaminated and non-contaminated classes of (a) $\mathrm{Cd}$ and (b) $\mathrm{Pb}$ classifications. 

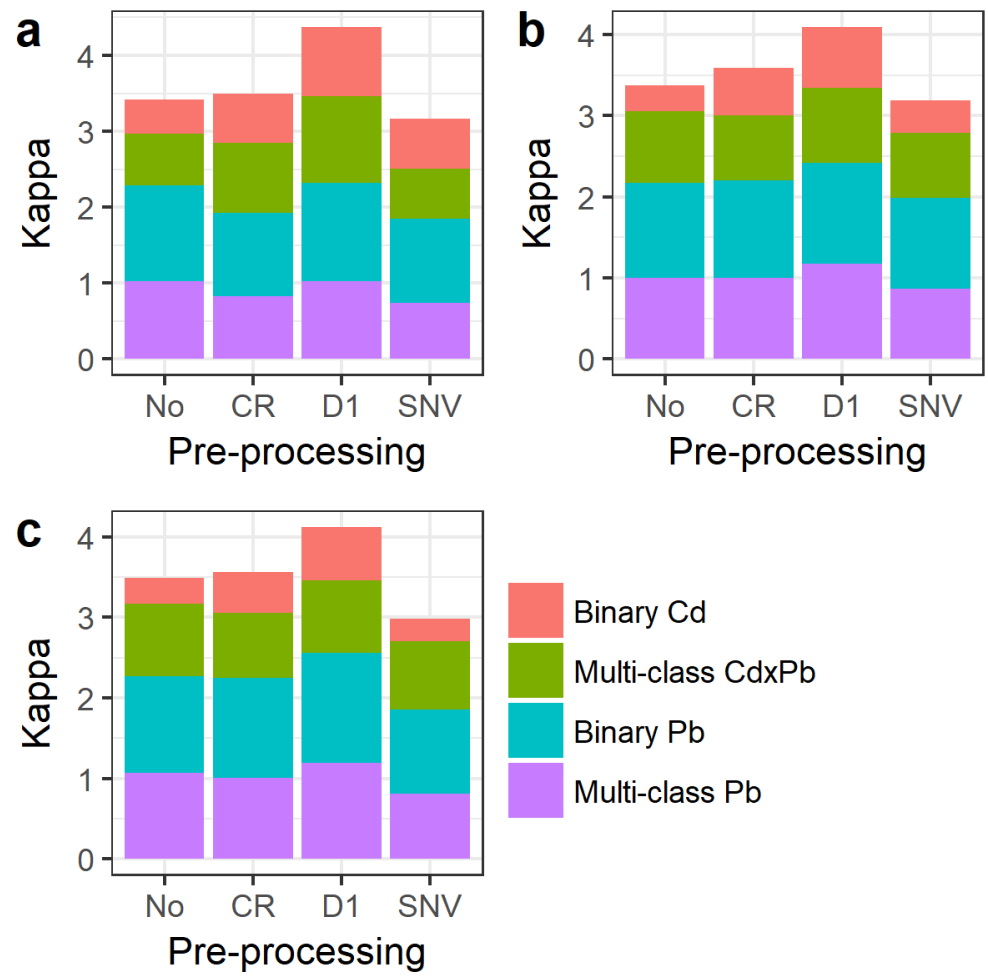

Fig. S3. Kappa coefficients of the PLS-DA classification for model (a) calibration, (b) validation and (c) VIP-based validation, when applied to the original reflectance data (no preprocessing) and three preprocessing types (D1 = first derivatives, SNV = standard normal variate, $C R=$ continuum removal). 